\title{
Multiculturalisme et laïcité en France : les trois républicanismes du rapport Stasi $^{1}$
}

\author{
KAREL LEYVA Université de Montréal/École pratique des hautes études \\ (Paris)
}

RÉSUMÉ : Dès les dernières décennies du XXe siècle, le républicanisme a été l'objet d'un intérêt renouvelé au sein de la théorie politique contemporaine. En France, c'est surtout à partir de 1989 que ce renouveau se constate. Certains défis posés par la diversité culturelle et religieuse occupent dès lors le devant de la scène philosophique, et il est possible de distinguer une pluralité de perspectives, chacune se réclamant d'interprétations spécifiques du républicanisme et, par conséquent, se positionnant différemment pour répondre à ces défis. Sur cet horizon, l'article situe le rapport de la Commission de réflexion sur l'application du principe de laïcité dans la République.

ABSTRACT: Since the late twentieth century, republicanism has been the subject of renewed interest in contemporary political theory. In France, subsequent to 1989, this revival brought debates about cultural and religious diversity to the philosophical forefront. Thus, it is now possible to distinguish between a plurality of perspectives, each claiming specific interpretations of republicanism and each positioning itself differently to meet these cultural and religious challenges. This article situates the Report of the Committee of Reflection on the Application of the Principle of Secularity in the Republic with regard to these issues.

1 Cet article a été rédigé lors d'un séjour de recherche à l'École pratique des hautes études, Paris. L'auteur tient à remercier le Conseil de recherches en sciences humaines du Canada (CRSH) pour son appui financier par l'entremise de la bourse Joseph-Armand Bombardier. Il remercie également les évaluateurs anonymes de la revue Dialogue pour leurs judicieux commentaires.

Dialogue 54 (2016), 647-684.

(C) Canadian Philosophical Association/Association canadienne de philosophie 2016 doi:10.1017/S0012217316000020 


\section{Introduction}

Le 11 décembre 2003 a été remis à Jacques Chirac, alors président de la France, le rapport de la Commission de réflexion sur l'application du principe de laïcité dans la République. Soucieux de concilier l'unité de la nation et le respect de la diversité, ce document formule 26 recommandations visant l'adaptation de la laïcité française aux nouveaux défis posés par la diversité culturelle et religieuse.

Le principe de laïcité, considéré comme «constitutif de l'histoire collective» de l'Hexagone (Stasi, 2003, p. 10), occupe une place de premier ordre dans la philosophie républicaine française. La laïcité se décline couramment en deux principes : le principe de séparation entre le religieux et le politique et le principe de la neutralité de l'État face aux diverses convictions religieuses ou philosophiques. Ces deux principes ne constituent pas des finalités en soi. Si le principe de séparation implique, entre autres, qu'aucune conviction religieuse ou philosophique n'a le droit de parler au nom de l'État et si le principe de neutralité, quant à lui, implique que l'État ne doit favoriser aucune de ces convictions, c'est justement afin de garantir l'égalité des citoyens et leur liberté de conscience. Les raisons le plus souvent avancées sont les suivantes : d'une part, si l'État n'est pas neutre, l'égalité entre citoyens est en danger, car la puissance publique est «en droit de traiter les individus différemment en fonction de leurs convictions religieuses, même lorsqu'une certaine liberté prévaut» (Jacquemain, 2014, p. 117); d'autre part, s'il n'existe pas de séparation entre le pouvoir religieux et le pouvoir politique, la liberté de conscience se voit menacée parce que l'exercice de la citoyenneté passe par l'adhésion de l'individu à la religion publique².

Historiquement, «la laïcité républicaine fait fond tout d'abord sur le principe d'autonomie du politique, qu'introduit dans le droit la Révolution de 1789» (Baudouin et Portier, 2001, p. 16). Si, avant les temps révolutionnaires, l'être humain était considéré comme dépendant vis-à-vis de Dieu, après 1789, on

2 Micheline Milot propose une définition de la laïcité qui résume cette description : «la laïcité correspond à un aménagement du politique où la liberté de conscience se trouve, conformément à une volonté d'égale justice pour tous, garantie juridiquement par un État neutre à l'égard des différentes conceptions de la vie bonne qui coexistent dans la société» (Milot, 2013, p. 20). On notera au passage que la laïcité ainsi comprise n'est pas exclusive au républicanisme français; elle est une composante essentielle de toute démocratie libérale, comme l'ont montré Jocelyn Maclure et Charles Taylor (2010). Ce qui semble être toutefois typique de la laïcité française, c'est l'appropriation par les républicains du principe libéral de séparation, formulé par John Locke dans sa Lettre sur la tolérance (1686), et la conjoncture historique de cette appropriation. Certains auteurs considèrent même que la Loi de séparation des Églises et de l'État (1905) est d'inspiration lockéenne (Agier-Cabanes, 2007; Baubérot, 2009, p. 16). «La laïcité "à la française” apparaît, dès lors, comme la fille d'un philosophe anglais connu pour être l'un des fondateurs du libéralisme politique, plutôt que comme celle des Lumières» (Agier-Cabanes, 2007, p. 137). 
attendra qu'il fasse preuve de sa capacité à mener une vie autonome, sans que la transcendance soit une référence nécessaire pour déterminer sa propre existence. Ce sera surtout durant la Troisième République (1870-1940) que l'exigence de laïcité en tant que principe républicain d'organisation sociale se mettra en place en France (Portier, 2002, p. 4; Hayat, 2013, p. 32) ${ }^{3}$. Un aspect important est à considérer dans toute analyse sur le sujet : dès ses débuts, la laïcité républicaine française a dû se construire en opposition au catholicisme, dont la conception transcendante de l'origine du pouvoir contraste avec la conception immanentiste des républicains. De nos jours, ce n'est plus l'Église catholique qui est au centre de l'attention, mais l'islam.

Ceci dit, le républicanisme n'est pas un corps doctrinal monolithique. Même dans un pays comme la France, où les valeurs républicaines semblent faire consensus, il existe d'importantes différences parmi les propositions concernant le modèle de gestion de la diversité à privilégier. Il ne suffit donc pas de considérer que le rapport Stasi se rattache à la tradition républicaine française; ce qui importe, c'est de l'examiner à la lumière des réponses que donne cette tradition à la diversité, afin de mieux le comprendre. Pour ce faire, la première partie de cet article s'attachera à examiner trois réponses qu'a données le républicanisme français à la diversité, notamment à partir des années 90 . Il s'agira ensuite de montrer que la littérature sur le rapport s'est focalisée sur la proposition d'interdire les signes religieux et que, ce faisant, on a négligé d'autres aspects, tout aussi importants. La dernière partie sera consacrée à mettre de l'avant ces aspects ignorés par la littérature savante.

\section{Trois réponses républicaines à la diversité en France}

En 1989, année du bicentenaire de la Révolution française, eut lieu ce que l'on appelle couramment l' «affaire du foulard», lorsque trois jeunes filles furent exclues d'un collège de Creil pour avoir refusé d'ôter leur voile. Cet évènement et d'autres qui l'ont suivi ont eu une incidence considérable non seulement sur l'accroissement de tensions identitaires en France, mais aussi sur la réflexion philosophique républicaine, dont le renouveau se constatera de plus en plus sur la scène médiatique et intellectuelle française (Bourdeau, 2007, p. 14).

3 En 1887, dans la première partie du Dictionnaire de pédagogie et d'instruction primaire, Ferdinand Buisson écrivait ainsi sur la laïcité : «Ce mot est nouveau, et, quoique correctement formé, il n'est pas encore d'un usage général. Cependant le néologisme est nécessaire, aucun autre terme ne permettant d'exprimer sans périphrase la même idée dans son ampleur» (p. 93). Il ajoute un peu plus loin : «[...] la grande idée, la notion fondamentale de l'État laïque, c'est-à-dire la délimitation profonde entre le temporel et le spirituel, est entrée dans nos mœurs de manière à n'en plus sortir. Les inconséquences dans la pratique, les concessions de détail, les hypocrisies masquées sous le nom de respect des traditions, rien n'a pu empêcher la société française de devenir, à tout prendre, la plus séculière, la plus laïque de l'Europe» (Buisson, 1887, p. 93). 
Certains défis posés par la diversité culturelle et religieuse occupent dès lors le devant de la scène philosophique, et il est possible de distinguer une pluralité de perspectives, chacune se réclamant d'interprétations spécifiques du républicanisme et, par conséquent, se positionnant différemment pour répondre à ces défis.

Nous utiliserons à cet effet la classification établie par le politologue anglais Jeremy Jennings dans son étude sur le républicanisme français des années 90 (Jennings, 2000), à savoir celle qui fait la distinction entre un républicanisme traditionnel, un républicanisme modernisé et un républicanisme multiculturel. Or, en reprenant cette typologie, nous lui attribuons un contenu plus large en y ajoutant des éléments plus récents du débat républicain sur la diversité. Il s'agira de la développer tout en l'adaptant aux propos qui sont les nôtres.

\subsection{Le républicanisme traditionnel}

Une première position, repérable dans le panorama philosophique sur la diversité, est celle du républicanisme traditionnel. Elle se caractérise par des points de vue critiques vis-à-vis de certaines expressions de la diversité souvent associées à la revendication de particularismes culturels et religieux, ainsi que par un rejet du multiculturalisme. Le républicanisme traditionnel soutient non seulement que le multiculturalisme appartient au monde anglo-saxon (Jelen, 1997; Landfried, 2007, p. 16), mais qu'il promeut aussi l'inégalité juridique, qu'il favorise le repli des communautés et qu'il place les cultures au-dessus de la politique et les groupes au-dessus des individus (Jennings, 2000, p. 589). Dans certains cas, on ira jusqu'à considérer que reconnaître des droits spécifiques aux minorités culturelles et religieuses, c'est vouloir que la France s'engage sur «la voie américaine de l'effervescence minoritaire», et que promouvoir des mesures de discrimination positive visant la réduction des inégalités culturelles, sociales et économiques, c'est s'attaquer aux principes républicains (Jelen, 1997), c'est «masquer le retour à une idéologie foncièrement réactionnaire» (Landfried, 2007, p. 95). Les multiculturalistes seraient «réactionnaires dans le sens littéral du terme» (Jelen, 1997, p. 138) et leur «idéologie» serait un puissant facteur de développement de l'extrême droite française (ibid., p. 143). Sous une politique multiculturelle, craignent certains auteurs, la France se scinderait progressivement en communautés ethniques, raciales ou religieuses «rivales, hostiles, séparées, réclamant, obtenant même leurs propres règles et leurs propres lois» (ibid., p. 143). Pour les républicains traditionnels, le droit à la différence est une «illusion multiculturaliste» (Todd, 1994) ${ }^{4}$.

4 «L'illusion multiculturaliste» est justement le titre du chapitre 5 d'un ouvrage d'Emmanuel Todd (1994, p. 95-107). Un peu plus loin, dans le chapitre 13, Todd écrit : «L'idéologie du droit à la différence n'a permis la préservation d'aucune culture émigrée, mais elle a largement contribué à la désorientation psychologique et sociale de la deuxième génération issue de l'immigration maghrébine. En retardant l'adhésion aux valeurs de la société française d'adolescents coupés de leurs valeurs d'origine, elle a été un facteur d'anomie» (Todd, 1994, p. 382). 
Certains auteurs soutiennent ainsi que le multiculturalisme se fonde sur un «respect inconditionnel» du droit à la différence, préférant se référer à la société multiculturelle en tant que «société multicommunautaire» (Taguieff, 2003; Landfried, 2007, p. 14). La diversité en soi ne poserait «aucun problème insoluble à la tradition républicaine dans sa variante française, marquée par l'idéal régulateur d'assimilation» et par le principe de laïcité : «[c]'est le multiculturalisme institutionnel ou le multicommunautarisme normatif, en tant qu'horizon ou projet politique, qui constitue une menace ou un défi pour la tradition républicaine à la française, notamment en ce qu'il s'attaque directement au principe de laïcité et à la norme juridico-politique d'égalité de tous les citoyens devant la loi» (Taguieff, 2003).

L'argument du repli communautaire et celui de l'inégalité, qui découleraient de politiques multiculturelles, reposent souvent sur une perspective qui fait de l'attachement à l'histoire et à la culture nationale française une condition sine qua non de la cohésion sociale. Le philosophe Guy Coq, par exemple, soutient que le "sentiment généreux» dont est issue la «volonté d'accueil des individus par un éloge de la société multiculturelle» ignore que «la cohésion sociale, l'intégration par la société, de tous ces membres, sont des phénomènes culturels, ont des conditions culturelles». C'est pourquoi un minimum de cohérence culturelle s'avère nécessaire si l'on ne veut pas que la société éclate «en mondes humains repliés, parfois ennemis, ambitionnant se constituer en véritables sous-sociétés concurrentes dans l'appropriation de l'espace commun» (Coq, 1995, p. 133). La cohésion sociale française, extrêmement fragile dès lors que la religion ne garantit plus le lien social (1995, p. 133; 2005, p. 11), n'a d'autre alternative que de reposer sur l'attachement à la culture et à l'histoire nationale française.

Cette perception des politiques multiculturelles, considérées non uniquement comme une menace pour les principes républicains, mais également comme un danger pour l'avenir de la société française, trouve son corrélat dans cette autre idée selon laquelle les revendications religieuses constituent un péril permanent pour les valeurs de la République. La question du port du foulard dans les écoles publiques françaises en est l'exemple le plus significatif. Souvent, l'argumentation de ce républicanisme procède selon une logique qui présente la société comme un champ de combat où s'affrontent sans cesse les différentes conceptions religieuses. Des groupes ou des individus opèrent systématiquement pour déstabiliser la République, dont les principes fondamentaux, tels que la laïcité et l'autonomie rationnelle, sont bafoués. Cela justifie une manière spécifique d'interpréter la laïcité comme étant une «laïcité de combat». Les corolaires de cette logique sont l'opposition au port des signes religieux à l'école publique et le consensus sur une loi les interdisant (Finkielkraut, 1989b; Badinter, Debray, et al., 1989; Coq, 1989 et 1995; Landfried, 2007).

Un cas idéal-typique de la position du républicanisme traditionnel en ce qui concerne la question du foulard est constaté dans les écrits de Coq. Cet auteur 
considère que, dans le contexte de la «montée des intégrismes», toutes les tentatives d'introduction du voile «jusque dans les salles de classe prennent un sens très précis : c'est la remise en question visible de la définition de l'école comme laïque» (Coq, 1989). Porter des signes religieux à l'école, ou, comme l'énonce Coq, «marquer l'espace scolaire de ses symboles» mettrait en péril le consensus conquis sur la laïcité. D'une part, ce serait céder aux exigences des musulmans traditionnalistes ${ }^{5}$ et, d'autre part, cela impliquerait qu'il faille donner ce droit à tous les groupes intégristes des autres religions. Dans cette perspective, le seul port du foulard est identifié au repli communautariste (Coq, 1995, p. 328) et à l'intégrisme ${ }^{6}$ : le foulard serait à la fois une marque d'appartenance religieuse renvoyant à une culture autre que la culture française, et un acte de revendication des groupes ou des individus qui manipulent les jeunes filles, leur imposant de porter le voile. Le seul port du foulard constituerait aussi le «principal risque de prosélytisme» dans les écoles (Coq, 1995, p. 282), car «le foulard en lui-même, du fait de sa seule présence, peut agir comme pression insidieuse sur les jeunes musulmanes traitées quotidiennement de "mauvaises" musulmanes par les jeunes voilées» (Coq, 1995, p. 267). Cette conception contraste avec l'avis du Conseil d'État qui, lors de

5 Selon Coq, l'affaire du voile aurait pris, entre 1989 et 1994, «la dimension d'une opération islamiste parfaitement menée» (1995, p. 277).

6 L'identification du foulard à l'intégrisme, l'attribution d'une volonté déstabilisatrice à des groupes qui opèrent contre la République et le recours à une laïcité de combat se retrouvent également dans le discours des certains politiciens. Jean-Pierre Chevènement, Ministre de la défense au moment des premières affaires relatives au voile, nous en fournit un bon exemple. Dans un article publié le 9 novembre 1989 dans Le Monde, il soutenait : «une poignée de jeunes filles, symbolisant le défi d'un islam intégriste, semblent faire vaciller l'école de la République sur ses bases». Le voile, identifié encore une fois à l'intégrisme, menacerait les fondements de la République. Devant cette menace, la perspective adoptée est exactement la même que celle épousée par les républicains traditionnels : «A-t-on oublié que la République fut toujours un combat?» se demande Chevènement. Pour lui, il faut «faire front» à ces nouvelles «formes d'obscurantisme»; c'est pourquoi «l'esprit de libre examen reste aussi nécessaire qu'hier à la République. Et par conséquent la laïcité» (Chevènement, 1989). Il ne faut pourtant pas interpréter la position de Chevènement qui, selon Dominique Schnapper, est «le ministre républicain par excellence», comme hostile à la diversité. Dans son discours du 15 février 1999 lors de la réunion des préfets, il a affirmé qu'«il convenait que la Police nationale soit à l'image de la population», en invitant les préfets à «permettre l'accueil, au sein des services de police, des jeunes issus de l'immigration» et à «diversifier les recrutements», et ce, «sans qu'il puisse être question de quotas» (Cf. Schnapper, 2004, p. 180). 
l'affaire du voile de 1989, a estimé que le seul port du foulard ne constituait pas, en lui-même, un acte de prosélytisme ou de pression sur les filles musulmanes. À l'instar d'autres républicains traditionnels (Badinter, Debray, et al., 1989; Finkielkraut, 1989b), Coq a critiqué la décision du ministre Jospin de s'appuyer sur cet avis pour choisir la voie de la négociation au lieu de celle de l'interdiction. $\mathrm{Si}$, pour certains (Badinter, Debray, et al., 1989), Jospin a trahi «la mission de l'école», pour Coq, le ministre aurait commis une «faute politique» avec «des conséquences très fâcheuses» permettant que les minorités islamistes qui manipulent les porteuses de foulards découvrent à cette occasion que la laïcité est un ventre mou, qu'au fond on pourrait sans trop de mal agir dans l'école pour déstabiliser l'idée laïque, et provoquer une grave crise au plan des principes de cette société laïque tant honnie. De plus, cette décision est aussi l'occasion de tenter de déstabiliser l'immense majorité des jeunes musulmans, qui ont fait le pas de l'intégration, mais que ce conflit monté sciemment peut perturber (Coq, 1995, p. 267).

Coq estime donc que porter sur soi «les signes ostentatoires de ses appartenances» n'est pas acceptable dans l'espace scolaire (Coq, 1995, p. 200) et qu'il convient de s'opposer à ce geste, «quels qu'en soient les auteurs : élèves ou enseignants» (Coq, 1989). L'adjectif «ostentatoire» mérite que l'on s'attarde sur sa définition. C'est justement le mot qui a été utilisé dans la circulaire du ministre François Bayrou proposant, en 1994, l'interdiction des «signes ostentatoires, qui constituent en eux-mêmes des éléments de prosélytisme ou de discrimination» ${ }^{7}$. Pourtant, ce document ne définit pas le mot, il se limite à l'opposer aux «signes discrets». La commission Stasi, quant à elle, utilisera quelques années plus tard le mot «ostensible» dans sa recommandation d'interdire les signes religieux dans les écoles publiques. Or, chez Coq, il ne semble pas y avoir de différence entre «ostensible» et «ostentatoire», puisqu'il appelle «affichage ostentatoire d'appartenance» celui que «le regard porté vers la personne ne peut éviter». Cet affichage ne serait pas souhaitable, car «il invite à regarder avant tout le membre d'une communauté particulière là où la laïcité impose de voir une personne unique, et un membre identique à tout autre de l'institution scolaire et de la société globale dont l'école a pour mission de symboliser l'unité et la cohésion toujours à refaire» (1995, p. 200). Coq a «l'intime conviction que le voile dans la classe représente un frein à l'intégration de beaucoup» (ibid., p. 328). Il faudrait donc l'interdire, et les membres des religions qui ne représentent pas une menace pour la stabilité de la République devraient aussi se conformer

7 Coq a qualifié cette circulaire de «très modérée», de «bien argumentée» et son ton de «juste». Quant à l'idée selon laquelle le «principal risque de prosélytisme» dans les écoles tient au foulard islamique, Coq considère que «cet avis est fort sage» (1995, p. 282). 
à cette $10 i^{8}$. «Que cette règle de discrétion doive, dans la classe, s'imposer aux autres religions, je l'admets. Et je ne serais pas choqué que les kippas et les croix ostentatoires soient également interdites par une circulaire ou une loi» (Coq, 1995, p. 328).

Terminons cette section en signalant que le républicanisme traditionnel s'attaque souvent aux justifications qui font des droits de l'homme un fondement pour autoriser le port des signes religieux dans les écoles. Dans certains cas, étant donné que les filles voilées sont perçues comme des objets de manipulation systématique et que le foulard est interprété comme un symbole de la soumission féminine, l'argument de la liberté de conscience s'effondre, tout simplement parce que «tolérer le foulard islamique, ce n'est pas accueillir un être libre» (Badinter, Debray, et al., 1989). Le respect de la différence n'est pas considéré comme un argument recevable, soit parce que le foulard, perçu comme contraire au principe de l'autonomie rationnelle et aux droits de l'homme, n'est pas respectable (ibid.), soit parce que «la différence revendiquée brise l'équilibre instable qui constitue l'espace laïque de la classe» (Coq, 1989). De plus, «l'absolutisation» des droits individuels ébranlerait les principes qui fondent le droit d'éduquer : «toute démagogie politicienne sur les droits nouveaux est quasi destructrice de l'espace laïque» (Coq, 1995, p. 200). Enfin, certains auteurs, tels que Finkielkraut, soutiennent que ce «retournement des droits de l'homme contre l'école laïque» ne serait pas seulement philosophiquement grotesque et moralement condamnable, il serait aussi un «crime politique» qui pourrait être payé très cher par la suite. Au nom de la tolérance,

8 On serait alors tenté de penser que l'on se trouve devant un cas où des communautés religieuses doivent accepter les effets inégaux de la neutralité étatique. En réalité, loin d'épouser la conviction selon laquelle l'État doit être neutre (que ce soit du point de vue de la justification, des conséquences, ou des buts qu'il se donne pour agir), la neutralité est, dans cette perspective, une notion qui affaiblit la République (Coq, 1995, p. 327). Ici et ailleurs, cet auteur insiste sur le fait que si la laïcité implique la neutralité religieuse de l'État, cela «laisse la possibilité qu'il ne soit pas neutre sur d'autres sujets» (Coq, 2012, p. 2). Se référant, par exemple, au domaine pédagogique, il affirme que «si l'éducateur est neutre, c'est un être insipide, sans profondeur, une humanité mutilée et, alors, il ne saurait être un bon éducateur» (1995, p. 156). L'auteur rappelle que Jules Ferry ne considérait pas la République comme étant neutre. Or, en réalité, les propos de Ferry n'étaient pas uniquement descriptifs, ils étaient surtout normatifs. De fait, dans son Discours au Sénat du 31 mai 1883, Ferry a tenu ces propos : «Nous avons promis la neutralité religieuse, nous n'avons pas promis la neutralité philosophique, pas plus que la neutralité politique» (Annales du Sénat, 1883, p. 261). Plus qu'une perspective descriptive, Ferry adopte donc un point de vue volontariste, qui nous semble correspondre à la perspective de Coq. De fait, si pour ce dernier il existe «un lien nécessaire» entre laïcité et république, c'est que ce lien suppose justement une «éducation forte» (Coq, 2005, p. 11). 
de la liberté individuelle et de la démocratie, les appartenances communautariennes s'exhiberaient «violement là où il était loisible jadis de les suspendre». Pour cet auteur, «nous ne savons plus faire la différence entre les droits de l'homme et les droits des tribus» (Finkielkraut, 1989a).

\subsection{Un républicanisme modernisé}

Examinons une deuxième position couramment identifiée comme républicanisme modernisé, et représentée par Dominique Schnapper. Cette dernière partage la préoccupation des républicains traditionnels quant au danger de repli identitaire que comporte le multiculturalisme. Elle considère pourtant que la prise en compte des particularités, même si elle ne favorise pas la conscience commune, «ne conduit pas immédiatement et nécessairement» au communautarisme, compris comme l'enfermement des personnes dans un groupe particulier, «aux dépens de leur conscience commune et de leurs relations, au-delà de leur groupe, avec les membres de la société plus large» (Schnapper, 2004, p. 180). Il revient aux institutions communes d'encourager l'ouverture des groupes. De la même manière qu'il intervient dans l'enseignement, les activités sportives et la culture pour assurer l'égalité réelle de tous les citoyens, l'État doit intervenir dans l'ordre ethnique, afin d'assurer des droits culturels là où ces derniers s'avèrent indispensables dans le but de garantir aux individus leur pleine authenticité.

Si l'on considère que l'identité personnelle n'est pas séparable d'une culture collective, l'État doit reconnaître les cultures particulières et lutter contre les discriminations dont certains ont été ou continuent d'être les victimes à cause de leur participation à cette culture. Le bien-être de l'individu ne comporte pas de limites, et l'État de la démocratie providentielle doit répondre à toutes les demandes qui visent à l'améliorer (Schnapper, 2004, p. 181).

Or, selon Schnapper, cette intervention étatique comporterait plusieurs risques. Tout d'abord, on risquerait d'enfermer les individus dans leur particularisme en les assignant à un groupe, ce qui serait contradictoire avec la liberté personnelle, car l'appartenance juridique à un groupe par la naissance irait à l'encontre de la liberté démocratique. Ensuite, la reconnaissance publique des groupes favoriserait le repli des individus sur leur communauté d'origine là où il serait nécessaire de donner les moyens de dépasser cette appartenance «et d'entrer en relation avec les autres $\gg{ }^{9}$. La reconnaissance des droits culturels fixerait alors, de manière permanente, les individus à leurs groupes, sans voir que ces groupes sont des constructions historiques susceptibles d'évoluer. Il s'agit du risque de fragmentation sociale que craignent les républicains traditionnels ${ }^{10}$, c'est-à-dire du danger de voir les communautés culturelles se juxtaposer les unes aux

9 Schnapper semble suggérer ici que le fait d'être attaché à une appartenance implique que l'on n'est pas lié à ceux qui ne partagent pas cet attachement.

10 Le risque de fragmentation est également admis par un multiculturaliste comme Will Kymlicka, qui conditionne, d'un point de vue libéral, la reconnaissance des droits culturels (Schnapper, 1998, p. 484). 
autres, fermées à l'échange. Finalement, on retrouve la question de l'égalité entre groupes et entre citoyens. Comment des groupes qui participent à des formes de citoyenneté différenciées peuvent-ils être égaux entre eux? Comment inscrire politiquement l'égalité de tous les citoyens et la reconnaissance des droits culturels? «Peut-on échapper à la contradiction entre la différence et l'égalité?» (Schnapper, 1998, p. 482) Schnapper mobilise les réponses que certains auteurs, qu'elle considère comme étant des «communautaristes modérés» ou des «multiculturalistes modérés», ont donné à ces problèmes, à savoir

a) le droit de sortie : aucun individu ne devrait être assigné autoritairement à un groupe : il doit rester libre d'y entrer et d'en sortir;

b) les seules cultures susceptibles d'être reconnues sont celles qui ne comportent pas de traits incompatibles avec les droits de l'homme ${ }^{11}$; et

c) il est nécessaire de garantir l'égalité entre les groupes.

La sociologue se montre philosophiquement en accord avec ces réponses :

On ne peut que souscrire aux aspirations des penseurs multiculturalistes modérés, directement inspirées par les valeurs de l'individualisme démocratique. Comment nier que l'ordre démocratique se donne pour légitimité d'offrir à chacun les moyens de développer toutes ses capacités, de se révéler à lui-même et aux autres dans sa pure authenticité? Comment nier que la société démocratique doive conjuguer l'égalité politique du citoyen avec les aspirations de l'individu enraciné dans une histoire et une culture particulières? (2004, p. 185).

Or, si Schnapper s'arrêtait à ce stade, il n'y aurait pas de différences entre sa position et celle des multiculturalistes.

Elle croit, il est vrai, que si l'on respecte les conditions énoncées par les «multiculturalistes modérés», l'on parviendrait à un «républicanisme tolérant» $\left(2004\right.$, p. 186) ${ }^{12}$. La citoyenneté, tout comme les différences culturelles, est en constante modification, et ce serait donc une erreur de cristalliser l'une et les autres. Elle pense également que la citoyenneté peut se vivre sans aucun problème dans le

11 La question, à notre avis, devrait se poser non pas en termes de cultures mais en termes de pratiques culturelles. On peut, par exemple, rejeter des pratiques culturelles ou religieuses propres à certaines interprétations de l'islam sans pour autant rejeter d'un seul trait la culture musulmane.

12 Schnapper ne distingue pas le républicanisme tolérant du libéralisme modéré : «Il s'agit, dans tous les cas, d'adopter ce qu'on pourrait appeler une forme de "libéralisme modéré" dans le vocabulaire anglophone - ou, en termes français, de "républicanisme tolérant" —, sensible aux conditions culturelles et sociales de la vie politique, mieux adaptée à la démocratie moderne que le libéralisme ou le républicanisme traditionnels, proposant des modes d'intégration plus souples et plus attentifs aux besoins des populations particulières» (Schnapper, 2004, p. 187). 
dédoublement de la personne, tant qu'on ne cherche pas à modifier les règles de fonctionnement politique : les individus doivent accepter l'existence d'un domaine politique indépendant de leurs intérêts particuliers et suivre les règles de gouvernement propres à ce domaine. Le multiculturalisme est un fait puisque toute nation est constituée de diverses populations du point de vue religieux, culturel et social (Schnapper, 1994, p. 99). Rien n'empêche les individus qui conservent le noyau dur de leur culture d'origine de participer à la vie professionnelle et collective, à la vie politique, si leurs normes ne contredisent pas les valeurs de la communauté de citoyens. Ainsi, les Sikhs portent leur turban dans l'armée du Canada, sans que cette coutume ne remette en question leur humanité, à la différence d'autres pratiques telles l'excision des fillettes ou l'esclavage (Schnapper, 2010, p. 36). Le multiculturalisme est également un droit, puisque l'ordre démocratique se fonde sur la séparation entre domaine public et domaine privé. «Si les spécificités culturelles des groupes particuliers sont compatibles avec les exigences de la vie commune, écrit Schnapper, les citoyens et les étrangers régulièrement installés sur le sol national ont le droit de cultiver leurs particularités dans leur vie personnelle comme dans la vie sociale, à condition de respecter les règles de l'ordre public» (Schnapper, 1994, p. 100).

Néanmoins, Schnapper considère que les politiques multiculturalistes varient selon les contextes socio-historiques de chaque pays, et qu'il s'avère nécessaire de prendre en compte «l'histoire de la formation de la nation et de la légitimité de l'ordre politique pour adopter des politiques de reconnaissance des droits culturels» (2004, p. 187). Si le républicanisme défendu par Schnapper n'est pas multiculturaliste, c'est que, pour elle, le rôle premier de l'État consiste à «organiser l'unité de l'espace politique commun, qui permet d'intégrer par l'abstraction et l'égalité formelle de la citoyenneté tous les individus, quelles que soient leurs origines sociales, religieuses, régionales ou nationales»» (ibid., p. 187, c'est nous qui soulignons). Et si, du point de vue démocratique, il est légitime que cet État réponde aux demandes de certaines populations particulières, au lieu de les refuser systématiquement, Schnapper estime, contrairement aux multiculturalistes, que «ce n'est pas son rôle que d'organiser et de subventionner les particularismes. Son abstention doit s'appliquer à l'égard des cultures particulières comme à l'égard des religions ${ }^{13}{ }^{13}$. En somme, si chacun

13 Schnapper (2004, p. 187-188). Ce passage a été repris par Schnapper dans un texte postérieur où elle substitue le mot «abstention» par celui de «neutralité» (Schnapper, 2007, p. 97). Or, à l'instar des penseurs multiculturalistes et communautariens, Schnapper considère que l'État n'est jamais neutre, mais elle se distancie d'eux quant à la solution apportée : «Il vrai que l'État n'est jamais véritablement neutre et que la culture commune, élaborée et garantie par les institutions publiques, s'impose aux cultures particulières, mais n'est-ce pas le prix à payer pour que tous les citoyens participent pleinement à la société nationale?» (Schnapper, 1998, p. 487). Pour une critique de cette position, voir Guérard de Latour (2009, p. 107-109). 
doit disposer de moyens pour participer à la vie commune, le «communautarisme» doit être laissé à la liberté et à l'initiative des individus, «encouragé par une application souple de la citoyenneté républicaine. Cela est conforme à la fois à la tradition de l'intégration française et à la légitimité des sociétés modernes, qui reposent sur l'universalité des droits du citoyen et de la protection de l'État-providence» (2004, p. 188).

La liberté et l'initiative des individus, dans l'organisation de leurs «communautarismes», ont pourtant des limites : les spécificités culturelles ou religieuses ne doivent pas être en mesure de fonder une identité politique particulière reconnue à l'intérieur de l'espace public, car cela contribuerait en effet à la dissolution de l'identité nationale «au profit des seules appartenances communautaires» (Schnapper, 1994, p. 100). Également, cela irait à l'encontre de ce qui constitue, pour cette auteure, l'essence du projet national, puisque la nation se définit justement «par son ambition de transcender par la citoyenneté des appartenances particulières», qu'elles soient religieuses, culturelles, économiques, sociales ou biologiques, au sein de laquelle le citoyen est défini comme un individu abstrait «sans qualifications particulières, en-deçà et au-delà des déterminations concrètes» (ibid., p. 50). Le projet national serait ainsi universel, parce que, d'une part, il est destiné à tous ceux qui habitent dans une même nation, et d'autre part, le dépassement des particularismes par le politique est susceptible d'être adopté dans toute société. «L'universalité est l'horizon de l'idéologie de la liberté et de l'égalité postulée des individus, fondatrice de l'idée de nation» (Schnapper, 1994, p. 49-50). L'universalité n'est donc pas un contenu, mais une idée régulatrice. Elle ne s'incarne pas dans une culture particulière. Elle réside plutôt dans la capacité de prendre une distance avec le donné immédiat, d'opérer une évaluation critique à l'égard de sa propre société (Schnapper, 2010, p. 37) et de transcender le privé pour se retrouver dans le public.

Bien que compatible avec le multiculturalisme dans une certaine mesure, le républicanisme modernisé reste attaché à une image idéalisée du citoyen abstrait (Heine, 2009). Comme les républicains traditionnels, Schnapper considère que toute communauté politique démocratique, devant se fonder sur une communauté de valeurs, trouve dans la nation, et dans ses ancrages historiques et culturels, le principe universaliste d'intégration par excellence. S'éloignant des républicains traditionnels lorsqu'elle admet, sous certaines conditions, des accommodements raisonnables et des droits culturels afin que les individus accèdent à l'égalité citoyenne, Schnapper ne va pas aussi loin que la troisième position identifiée : le républicanisme multiculturel.

\subsection{Le républicanisme multiculturel}

Le républicanisme multiculturel cherche à répondre à la diversité culturelle et religieuse par l'inclusion sociale des individus et des groupes appartenant à des cultures distinctes de la culture dominante, se montrant favorable aux droits 
culturels et à la reconnaissance publique de la différence ${ }^{14}$. Ses tenants acceptent la légitimité des revendications culturelles et religieuses comme faisant partie de l'exercice actif de la citoyenneté et autorisent la mise en place d'accommodements afin de traiter également les individus. Ils prônent donc le multiculturalisme comme modèle d'intégration envisageable pour la France contemporaine, se situant aux antipodes du républicanisme traditionnel, auquel souvent ils se réfèrent tout simplement comme «républicanisme français». Le philosophe Joël Roman et les sociologues Michel Wieviorka et Farhad Khosrokhavar ${ }^{15}$ peuvent être situés dans ce courant.

Roman, par exemple ${ }^{16}$, comprend les revendications culturelles en France, notamment celles de l'islam, dans un cadre caractérisé par la «perpétuation de l'humiliation coloniale» où le racisme et les ségrégations sociales sont à l'œuvre. Il croit possible de «corriger quelque peu les tendances centripètes de la société française en lui injectant quelques doses de multiculturalisme [...]» (1995, p. 150-151). Afin de «déconstruire» le républicanisme français, cet auteur analyse les trois postures en présence dans le débat sur le multiculturalisme. Tout d'abord, la posture libérale, attachée aux droits individuels, face

14 Pour retracer le débat contemporain sur les théories de la reconnaissance, voir Gutmann (1994); Taylor (1994); Habermas (1998); Fraser (2000 et 2005); Morag (2000); Galeotti, (2002); Ricœur (2004); Tully (2004); Triki-Yamani et Mc Andrew (2009) et Honneth (2013).

15 À la différence du républicanisme défendu par Schnapper, qui fait de la nation le principe d'intégration sociale par excellence, les travaux de ces sociologues se situent dans une perspective d'intégration post-nationale, «estimant que les sociétés post-industrielles reposent sur un mode d'intégration qui rend les institutions traditionnelles du nation-building process obsolètes» (Guérard de Latour, 2009, p. 89, note 26).

16 Il convient cependant de signaler que F. Khosrokhavar et M. Wieviorka, qui, selon Jennings (2000), défendent un républicanisme multiculturel, ont été considérés ailleurs parmi les critiques externes du républicanisme, prônant une position multiculturaliste soit de gauche radicale soit de la Nouvelle gauche (Laborde, 2001, p. 721). Dans une étude postérieure, Jennings se réfère au multiculturalisme républicain français comme étant un républicanisme élargi, tout en admettant que «What such a republicanisme élargi would look like is not as yet easy to discern but there is an acknowledgement that it might entail a substantial recasting of some hallowed republican principles. There is in particular an awareness that a tension exists between the republican values of liberty and equality and the multicultural values of difference and equality» (Jennings, 2011, p. 525). Néanmoins, cette tension trouve une solution, à notre avis, dans le républicanisme multiculturel qui se développe notamment dans le monde anglo-saxon, sans que les principes centraux du républicanisme philosophique ne soient modifiés. Voir Tully (2001 et 2004); Maynor (2003) et Honohan (2007). 
auxquels l'État trouve des limites, est caractérisée par une conception selon laquelle la société est constituée de liens juridiques. Ensuite, la posture «communautaire» dénonce cette conception individualiste libérale en prônant la recherche du bien commun, susceptible d'être trouvé dans les traditions propres à chaque communauté politico-culturelle. Enfin, la posture multiculturaliste met de l'avant le besoin de l'individu de se référer à une sous-culture l'instituant dans sa différence, que cette sous-culture se rapporte au genre, à l'orientation sexuelle, à la culture d'origine ou à l'ethnie. Le multiculturalisme s'allierait avec le libéralisme pour faire front contre la vision de l'identité commune ou du bien commun, typique d'un communautarisme qui ne tient pas assez compte des différences individuelles. Il se rattacherait au communautarisme dans la dénonciation de l'abstraction libérale et de sa vision du lien social en termes juridiques. Selon Roman, le fait que le républicanisme français soit hostile au multiculturalisme s'explique dès lors qu'on le comprend comme une conjonction de libéralisme et de communautarisme ${ }^{17}$ :

Liberal, le républicanisme français l'est dans la mesure où il valorise plus que tout l'autonomie de l'individu, en tant que celui-ci est censé d'obéir à la seule raison. Mais il n'est pas moins communautaire, puisqu'il fait de l'inscription de cet individu dans une singularité historique (l'exception française) et de sa prise en charge par l'État la condition de son émancipation. Quand on parle maintenant d'introduire le multiculturalisme dans la tradition française, c'est d'abord à une mise en perspective de cette synthèse opérée par le républicanisme que l'on songe (Roman, 1995, p. 153; 1998, p. 212).

Roman propose ainsi un multiculturalisme à la française (1995 et 1998), capable de reconnaître, en plus de la diversité de la société et des groupes qui la composent, la nécessité pour les individus de construire leurs identités sur la base des appartenances multiples ${ }^{18}$. Ce multiculturalisme se veut également apte à favoriser la visibilité de la différence dans l'espace public (y compris

17 Cette manière de comprendre le républicanisme rejoint celle de Sophie Heine (2009) et contraste avec celle défendue par Justine Lacroix, selon qui on peut être libéral et républicain, de même que l'on peut être communautarien et républicain, mais on ne peut être à la fois libéral et communautarien (Lacroix, 2003, p. 15).

18 Déjà en 1990, Roman écrivait qu'il ne fallait pas exclure a priori la reconnaissance de communautés particulières au sein de la nation. Bien qu'il songeait ici notamment aux cadres infranationaux (régionaux, municipaux), voire supranationaux (européens), il remettait en question l'idée selon laquelle la nation est le seul cadre légitime d'appartenance : «Simplement, la nation ne me paraît plus en mesure de symboliser à elle seule l'appartenance politique, comme la tradition républicaine l'avait consacré» (Roman, 1990, p. 79). 
l'espace médiatique), à organiser la confrontation entre groupes pour interdire le repli sur soi des différences, à impulser une dynamique nouvelle aux relations entre l'État et la société qui emprunte la voie de la discrimination positive, là où il s'avère nécessaire de corriger les inégalités de fait, discrimination qui «ne cible pas les groupes», mais qui favorise une action différenciée de la part de l'État. Il s'agit de trouver une voie moyenne, un «multiculturalisme tempéré», qui refuse tant les enfermements communautaires que l'individualisme libéral (Roman, 1996, p. 20).

Ces points de vue (notamment, la critique du «républicanisme français», le respect du droit à la différence, la reconnaissance publique des particularismes, la concession de droits culturels aux individus et la défense d'un multiculturalisme tempéré), se trouvent également dans les écrits de Michel Wieviorka. Ce dernier estime en effet que le débat sur la diversité en France a été largement dominé par un républicanisme qui va de l'assimilationnisme à la tolérance et qui, par naïveté ou par ignorance, accuse ceux qui favorisent un multiculturalisme tempéré de faire le jeu du communautarisme $(1998$, p. 251). Le discours du républicanisme français fonctionnerait à la fois comme mythe et comme idéologie, développant une image artificielle du passé et du présent, afin de concilier ce qui ne peut pas l'être dans la réalité, et ce, de manière incantatoire, irréelle et abstraite : "Tourné vers le passé, le "républicanisme" avance vers l'avenir à reculons, et en paralysant d'autant plus la réflexion sur les changements culturels et la place qu'ils réclament que les communautés qu'il invoque sont en bonne partie de l'ordre du fantasme, ou traitées de manière fallacieuse, alors que les plus actives ne sont qu'exceptionnellement ou accessoirement invoquées» (Wieviorka, 1998, p. 251).

Le républicanisme français manque donc de fondements sociologiques. Il s'attaque à l'islam par exemple, en le mettant, en relation avec la délinquance et en le qualifiant de communautariste. Or, d'un côté, la violence des «quartiers de relégation» n'est pas commise par des musulmans, mais par des jeunes sans aucun attachement religieux. De l'autre, la «hantise du communautarisme» ne vise pas les communautés de Portugais ou d'Asiatiques, dont le style de vie est beaucoup plus communautaire que celui d'autres immigrés communément ciblés par les républicains. Lorsque la critique du multiculturalisme provient de la droite ou de l'extrême-droite, elle vise en réalité une «nébuleuse sémantique» qui regroupe l'immigration, le terrorisme, la délinquance, l'insécurité et, surtout, l'islam (Wieviorka, 2011).

Or, selon cet auteur, la mise en relation du multiculturalisme et de l'islam ne va pas sans poser de problèmes, puisque «le multiculturalisme, qui traite de cultures, n'est pas adapté pour traiter de religion» (Wieviorka, 2015). Critiquer le multiculturalisme en ce qu'il répond aux défis que pose la religion musulmane est donc tout simplement inadéquat. Même si la culture et la religion se chevauchent, cette dernière doit être traitée différemment d'un point de vue institutionnel et politique. Elle relève plutôt des principes de séparation et 
d'articulation du religieux et du politique, comme la laïcité ${ }^{19}$. Si l'on parvient à considérer que la religion se trouve en dehors du cadre multiculturel, les problèmes à traiter à l'intérieur de ce cadre sont des difficultés mineures, les enjeux étant faibles et les groupes concernés peu nombreux. Il ne resterait, par exemple, que les particularismes des homosexuels, des minorités issues de migrations souvent anciennes ou des tsiganes. La conclusion qui s'ensuit est que le multiculturalisme n'a pas failli, comme on l'annonce souvent, mais que le débat s'est déplacé vers des questions pour lesquelles il n'est tout simplement pas outillé. Ce qui importe dans le multiculturalisme, c'est la promotion des droits culturels, c'est-à-dire le droit individuel de vivre la culture de son choix, à condition qu'elle ne remette pas en cause les valeurs universelles et que ces droits soient confiés aux seuls individus et non pas aux responsables ou aux chefs de file des communautés. Le multiculturalisme tempéré doit également être expérimenté avec prudence et faire l'objet d'évaluations régulières. Soucieux de concilier le droit, la raison et le respect des différences, le multiculturalisme serait même une occasion à saisir pour la gauche (Wieviorka, 2011). En fin de compte, la réalisation de cette «belle idée» qu'est la République est de moins en moins efficace. Cette dernière tend à apparaître comme «un universalisme abstrait, une promesse superbe, mais qui n'est plus tenue, et en tous cas pa[s] pour tous» : la devise républicaine «Liberté, égalité, fraternité», visible dans les écoles, ne semble pas être faite pour les jeunes issus de l'immigration maghrébine, qui habitent dans des ghettos urbains régulièrement confrontés au racisme et aux interpellations policières (Wieviorka, 2013).

Cette dénonciation de l'universalisme républicain rejoint les critiques exposées par Farhad Khosrokhavar, pour qui le refus de reconnaître les particularités culturelles et religieuses à certaines populations a contribué à ce que des franges importantes de jeunes ne se retrouvent pas dans le modèle républicain. Pour cet auteur, l'idéologie républicaine est devenue répressive au lieu de devenir libératrice, ayant rejeté le droit à la différence; elle a manqué à sa promesse d'égalité, elle a dénié la capacité effective de participation de ces populations à l'universalité. En proclamant l'intégration de tous, au nom de l'universel, elle les a exclus dans les faits, puisqu'elle leur a retiré la possibilité de recourir à des mécanismes particularistes et communautaires. Crispé sur lui-même, l'universel déshumanise les exclus et donne une image déviante de l'autre pour peu que celui-ci «s'écarte des impératifs républicains, eux-mêmes rigidifiés» (Khosrokhavar, 1997, p. 150). Le républicanisme devient ainsi, et de plus en plus, intransigeant, monolithique, «à mesure que sa capacité d'entraîner l'adhésion des uns et des autres s'amenuise» (ibid., p. 150).

19 Wieviorka critique cependant l'usage qui est couramment fait en France de la laïcité, car souvent cette dernière devient un combat défensif, «fréquemment soupçonnée d'être mise en avant pour mieux humilier l'islam, résister à sa présence ou s'y opposer» (Wieviorka, 2013). 
Cette idéologie de l'universel abstrait rend difficile la gestion concrète de la diversité, car elle ne tient pas compte du contenu des différences; elle incite les groupes dominés à intérioriser l'indignité dont ils sont victimes. Ainsi, au nom de l'insertion de chacun dans la nation, l'universel abstrait devient un alibi pour le refus de la reconnaissance de l'autre. Il fait violence aux minorités défavorisées lorsqu'on les démunit, lorsqu'on les atomise, en leur faisant intérioriser précisément des traits inversés de valeurs universalistes promues par la République, tels que l'indignité, l'impossibilité de s'appuyer sur les autres ou la méfiance profonde vis-à-vis des proches. Dans une société où les expressions des particularismes dans l'espace public portent atteinte aux interdits culturels majoritaires, le minoritaire devient illégitime, il dérange la majorité. Le poids que certaines minorités doivent alors supporter peut même contribuer à les pousser vers la radicalisation, faute de toute reconnaissance. En effet, le refus de reconnaître toute identité communautaire contribue à la création de néo-communautés délinquantes, comme le refus de reconnaître l'islam des jeunes, de même que le lien social que cette religion est destinée à créer chez des groupes fragiles et déstructurés, risque de contribuer à la radicalisation.

L'idéologie républicaine de l'universel abstrait repose sur deux présupposés concernant la place de la diversité dans la sphère publique. Selon le premier, l'espace public doit être homogène, les particularismes religieux et culturels étant censés s'exprimer dans la sphère privée. Quant au second, il concerne le rôle-clé accordé au politique dans la structuration de l'identité publique des membres de l'État-nation :

Tant que la croyance à ce modèle opère pour l'écrasante majorité, ce modèle normatif ${ }^{20}$ opère comme un fait allant de soi. Que survienne la crise qui remet en cause cette évidence primordiale de la conscience nationale et, dès lors, l'équilibre entre le politique et le social se rompt. Plus le particularisme est banni du champ public et plus, par un effet de compensation, se «surpolitise» tout phénomène public. Ainsi une affaire comme celle des foulards se trouve-t-elle dotée d'un sens «politique» là où, compte tenu de ses dimension et de son contenu, elle aurait dû faire l'objet de mesures et de négociations ad hoc et locales, à l'abri de toute politisation intempestive (Khosrokhavar, 1997, p. 129).

La politisation de l'affaire du foulard n'est donc pas purement accidentelle; elle traduit précisément des modes de gestion de la diversité dans l'espace public. Faire ôter le foulard de la tête des filles musulmanes ou les exclure de l'école est, en réalité, un exorcisme dont la fonction est de rassurer «une conscience nationale angoissée par la perspective de sa propre crise» (ibid., p. 126). Ce qui est en jeu dans cette affaire, ce n'est pas le foulard en soi, mais la signification qu'on en donne, qui est celle de l'islamisme politique ou du militantisme

20 Tous les mots soulignés dans les citations le sont par Khosrokhavar. 
religieux. Ainsi, les républicains qui dénoncent le port du foulard ne tiennent pas compte de la situation concrète des filles musulmanes qui, pour eux, n'existent que comme des êtres manipulés par des islamistes ou comme des sujets diaboliques incarnant l'antidémocratie. Ces républicains opèrent donc à partir de «principes intangibles». Les filles n'ont jamais été entendues ${ }^{21}$.

Or, c'est justement parce que, dans le débat sur le port du voile, les voix des filles musulmanes n'ont pas été prises en compte, que Françoise Gaspard et Khosrokhavar (1995) ont tenté de comprendre le phénomène, non pas à partir de principes abstraits ou de suppositions, mais sur la base de données empiriques obtenues par le truchement d'une étude de terrain menée dans les banlieues, notamment dans les quartiers dits «chauds». Cette étude leur a permis de tirer des conclusions opposées à celles soutenues par des républicains traditionnels.

Tout d'abord, là où les républicains traditionnels affirment que les filles portent le foulard parce qu'elles sont manipulées, étant sous la pression de leurs parents ou des islamistes, les sociologues montrent que la réalité est beaucoup plus complexe. Dans certains cas, le voile serait en effet imposé par les parents; cependant, on trouve également des cas où le port du voile est assumé ou revendiqué par de jeunes post-adolescentes, ainsi que d'autres où il est interprété par les jeunes musulmanes comme étant l'expression d'une expérience authentiquement religieuse, sans être réduit au respect des commandements islamiques. Le voile n'aurait donc pas un sens identique chez les jeunes filles. Ainsi, nombre d'entre elles se sentent en position d'infériorité à cause de leur origine sociale et ethnique; assumer le voile leur permet de se sentir dignes non seulement dans leurs propres quartiers, où souvent elles ne sont pas traitées à égalité avec les hommes, mais également dans une société qui les dévalorise, les traitant de «beurettes» (Gaspard et Khosroskhavar, 1995, p. 205). La recherche montre alors que les filles qui portent le voile ne sont pas nécessairement manipulées; il s'agit souvent d'un choix. Tel fut le cas, par exemple, de celles qui ont décidé de manifester à Grenoble, en janvier 1994, pour soutenir Shérezade, lorsque cette dernière a été exclue d'un lycée pour avoir porté le foulard, car la grande majorité des parents et des frères de ces filles n'étaient pas islamistes. Ce fut également le cas des filles exclues de collèges et de lycées en 1994, suite à la circulaire du ministre Bayrou, car celles-ci n'étaient pas associées aux islamistes (ibid., p. 211). Dans cette optique, il s'agit non

21 Laborde rejoint cette critique, plus d'une dizaine d'années après, dans le cadre de sa théorie de la non-domination : «Il semble que les femmes et les filles musulmanes voilées aient été entièrement dominées durant les débats officiels qui leur étaient consacrés. Privées d'auditions par la commission Stasi, assimilées à des pauvres être manipulés et incapables de parler en leur nom propre, et en proie à des croyances obscurantistes et rétrogrades, elles ont vu leur statut discursif nié. On a beaucoup parlé d'elles, mais elles-mêmes n'ont pas parlé. En ce sens, elles ont été dominées» (Laborde, 2010, p. 54). 
de nier l'existence des associations islamistes ou la pression que ces dernières exercent sur certaines jeunes filles, mais de montrer que le phénomène, s'expliquant en partie par la virulence du rejet des musulmans par la société française, était, au moment de la recherche, conjoncturel et marginal (ibid., p. 204).

Ensuite, là où certains républicains traditionnels, tels Coq, affirment que le foulard constitue forcément un frein à l'intégration, la recherche menée par Gaspard et Khosroskhavar montre que, paradoxalement, le voile se traduit tout au contraire par une volonté d'intégration des jeunes musulmanes, à qui le port du voile permet de négocier et d'apprivoiser la distance qu'elles trouvent entre la communauté de leurs parents et la société française : «le voile des post-adolescentes qui se réclament d'une "identité voilée" ne peut être interprété comme un rejet de la citoyenneté française, mais comme une volonté d'intégration sans assimilation, une aspiration à être françaises et musulmanes» (Gaspard et Khosroskhavar, 1995, p. 204). De fait, la recherche sociologique montrerait que les filles voilées ne comprennent pas l'opposition postulée entre elles et la République.

Finalement, là où les républicains traditionnels se montrent favorables à l'interdiction du port du voile dans les écoles publiques, Gaspard et Khosroskhavar considèrent qu'exclure les filles de ces écoles aurait l'effet inverse de celui que l'on recherche : ce serait mettre ces filles, déjà largement désavantagées, à la merci des communautaristes; ce serait les pénaliser au lieu de les émanciper par à l'éducation; ce serait également opposer les arguments de la cohésion républicaine à ceux de la tolérance démocratique, sans voir que les notions de République et de démocratie sont complémentaires. Dans le contexte de la France $^{22}$, une telle interdiction reviendrait à

désigner une fois de plus une partie de la population, celle qui est issue de l'immigration venue des pays musulmans, comme cible de toutes les peurs de la société. Si le voile est, en soi, si dangereux, alors pourquoi ne pas aller jusqu'au bout de la logique en interdisant tous les voiles, celui des religieuses comme celui des musulmanes? Et partout! Dans la rue, au bureau, dans les transports en commun, à l'université... Mais que resterait-il de la République dont la laïcité, c'est-à-dire la neutralité, est l'un des piliers (Gaspard et Khosroskhavar, 1995, p. 210)?

Tout conflit, concluent les auteurs, a besoin d'un adversaire réel, ce qui n'est pas le cas dans le combat mené contre le foulard, où les filles voilées ont servi

22 Ces auteurs considèrent d'ailleurs que l'idée de l'État-nation est l'un des multiples enjeux non mentionnés dans le débat sur le voile. Pour eux, l'État-nation serait «confronté à la question de l'immigration en même temps qu'à sa dissolution dans l'Union européenne» (Gaspard et Khosrokhavar, 1995, p. 12), ce qui ne va pas sans rappeler le constat fait par la commission Bouchard-Taylor par rapport aux tensions qu'expérimente la nation québécoise, minoritaire culturellement et linguistiquement en Amérique, majoritaire par rapport à son immigration. Voir Bouchard et Taylor (2008). 
d' «ersatz d'adversaire». D'une part, la recherche sociologique montre que la majorité de ces filles ne sont pas ce qu'on dit d'elles. D'autre part, leur exclusion de l'école, loin de faire reculer l'islamisme ou le terrorisme, peut être exploitée par les intégristes afin de susciter des solidarités. Enfin, étant donné que, dans le combat contre le voile, on n'a jamais donné la parole aux filles voilées, on ignore souvent que ces dernières «sont presque toutes des citoyennes de la République française, et qui, pour la plupart, s'assument comme telles» (Gaspard et Khosroskhavar, 1995, p. 33).

Khosrokhavar (1997, p. 150-151) propose alors de trouver de nouvelles formes de compromis historique, de nouvelles formes de gestion de l'espace public. Entre le multiculturalisme radical «imputé aux États-Unis» et le monoculturalisme français, intransigeant et ossifié, il existe une large place pour penser l'articulation entre le particulier et l'universel. Le problème en France n'est pas celui de l'excès «d'un éventuel multiculturalisme», il est «dans la nature monolithique et de plus en plus rigide et intransigeante d'une conception de soi et de l'autre qui entend exorciser l'angoisse par le refus de la diversité et, surtout, par le rejet de la pluralité». Au lieu d'adopter la voie de la répression de l'islam néo-communautaire dans le but de désamorcer le radicalisme, il importerait d'accorder une reconnaissance limitée aux particularités culturelles et religieuses dans la sphère publique. Il faudrait également se montrer ouvert à l'égard des filles musulmanes, dont le port du voile faciliterait l'intégration, afin qu'elles puissent manifester leur religiosité au sein de la société. Les formes radicales de républicanisme doivent être remises en cause. Une nouvelle synthèse, «républicaine» et «démocratique» ${ }^{23}$, s'avère nécessaire.

\section{La conception républicaine du rapport Stasi}

\subsection{Réception universitaire}

Si la commission Stasi a fait l'objet de nombreux travaux universitaires ${ }^{24}$, elle n'a été que rarement examinée du point de vue républicain. Ce sont surtout sa

23 Cette articulation ne va pas sans rappeler la tribune «Êtes-vous démocrate ou républicain?», parue sous la plume de Régis Debray dans le Nouvel observateur du 30 novembre 1989, suite à la première affaire du voile. Debray propose un «jeu de société» consistant à savoir «qui est quoi». Selon le philosophe, Jean-Pierre Chevènement, partisan de l'interdiction du foulard, est républicain, car il «a rendu son honneur à l'école, mais Joxe admet volontiers le "foulard" dans l'école publique» (Debray, 1989b).

24 Dans ce qui suit, nous laissons de côté les études comparatives abordant la commission Stasi (Adelman, 2011; Crépon, 2008; Gedicks, 2006), celles qui se penchent sur son entourage médiatique (Doyle, 2011; Gemie, 2004; Thomas, 2008) et celles qui s'intéressent aux réactions suscitées par la loi de 2004, soit chez certains politiciens et intellectuels (Chaudhary, 2005), soit chez des communautés religieuses (Vichniac, 2008). 
recommandation d'interdire les signes religieux dans les écoles publiques et la loi qui en a découlé qui ont monopolisé l'attention des chercheurs, ces derniers s'étant montrés, en général, critiques à l'égard de la commission et de son rapport.

Parmi les critiques les plus courantes adressées à cette commission, mentionnons celles qui remettent en question la justification de sa mise en place, soit parce qu'on considère la question du voile comme exigüe (Terray, 2004) ${ }^{25}$, soit parce qu'on estime que la commission a été érigée ad hoc afin de justifier rationnellement des préjugés sur la religion et de légitimer une décision qui avait été prise a priori (Liogier, 2009, p. 37). Certains s'attaquent également à la neutralité de son fonctionnement en rappelant les conditions particulières dans lesquelles la commission a vu le jour, ainsi que des évènements du contexte historique et sociopolitique français qui, conjugués avec d'autres facteurs microsociologiques ${ }^{26}$, ont conditionné d'importantes prises de décision. La neutralité de la commission aurait été compromise (Baubérot, 2004 et 2008), à cause non seulement de la pression politico-médiatique ${ }^{27}$, mais aussi des influences que le président, le rapporteur et certaines personnes non membres de la commission auraient eu sur le rapport final ${ }^{28}$. Ces facteurs, ajoutés au mauvais fonctionnement de la commission, auraient été déterminants pour le résultat final.

Une revue de littérature sur les analyses du rapport, plus pertinentes pour notre étude, révèle que la plupart d'entre elles critiquent les arguments qui ont été mis de l'avant afin de justifier la recommandation d'interdire les signes religieux dans les écoles publiques (Adrian, 2006), tout en discutant le principe de laïcité (Pelletier, 2005; Choudhury, 2007) ${ }^{29}$. Il existe même des travaux sur la plus récente loi interdisant la dissimulation du visage dans l'espace public (2010) qui font référence au rapport Stasi comme étant un antécédent à considérer (Hunter-Henin, 2012). C'est dans cette perspective qu'il convient de situer les études qui contestent la légitimité de cette loi : celle-ci soulèverait

25 À l'instar de Baubérot (2004 et 2008), cet anthropologue français qualifiera de redoutable le processus des auditions menées lors des travaux de la commission.

26 Pour une analyse sociologique détaillée de la commission Stasi, voir Baubérot (2012).

27 Néanmoins, Patrick Weil, lui aussi membre de la commission, affirme ne jamais avoir travaillé sous la pression publique. Voir Weil (2005).

28 Selon Jean Baubérot, une note relativisant le danger de l'islamisme, proposée par lui-même, et validée par le reste de la commission, n'a pas été incluse dans le rapport final (Belbah et Galembert, 2008).

29 Pelletier explore ici les critiques formulées à propos de la loi de 2004. D'après l'auteur, la loi serait injuste et renforcerait la violence dont sont victimes les femmes qu'elle prétend protéger : «elle les renvoie au milieu qui les opprime, elle les isole de l'institution scolaire qui devrait les émanciper» (Pelletier, 2005, p. 173). Il s'agit d'une opinion partagée par Akan (2009) ainsi que par Gaspard et Khosroskhavar (1995). 
d'importantes questions concernant la politique constitutionnelle, la théorie politique libérale et la formation de l'identité. Sur la base du principe de laïcité, l'État français chercherait à légitimer ce qui semble constituer de graves atteintes aux libertés religieuses et aux minorités culturelles. Le rapport Stasi a été vivement critiqué pour plusieurs raisons. Premièrement, il n'a pas apporté de preuve soutenant l'affirmation selon laquelle il existe une menace islamiste pour l'ordre public. Deuxièmement, il ne s'est pas engagé dans une discussion sérieuse sur les droits en cause. Troisièmement, il contient des inconsistances conceptuelles, notamment en ce qu'il recommande d'appliquer une contrainte afin de faire face aux pressions supposément subies par les jeunes filles musulmanes. Finalement, il n'a pas démontré que l'interdiction du voile à l'école pouvait avoir des effets positifs. La recommandation en question reposerait sur des motifs douteux, qu'ils soient d'ordre juridique ou public (Leane, 2011). Par ailleurs, on souligne que le rapport comporte une résurgence de l'idée d'assimilation comme objectif primaire de la politique gouvernementale française, ainsi qu'un affaiblissement du mouvement en faveur du droit à la différence. Cette politique assimilatrice fait obstacle à l'intégration des groupes d'immigrés musulmans (Freedman, 2004). La position du rapport Stasi, sur la question du voile, s'avère ainsi comme une nouvelle délimitation juridique de la liberté d'expression religieuse ${ }^{30}$, marquant une nette rupture avec la logique précédente du gouvernement français (E. R. Thomas, 2006). En effet, alors même que, selon certains, la France penchait vers le multiculturalisme, notamment avec l'établissement du Conseil français du culte musulman et la création d'écoles secondaires musulmanes sous contrat avec l'État, le rapport Stasi prenait des distances avec la laïcité inclusive qui caractérisait le modèle français précédent, en avançant vers une laïcité exclusive ${ }^{31}$. Ce constat se fonde, encore une fois, sur la recommandation d'interdire les signes religieux à l'école :

30 Paul Cliteur soutient pour sa part le contraire. Dans son analyse des modèles classiques de relation entre l'État et la religion, le philosophe néerlandais considère que certaines valeurs énoncées dans le rapport (l'égalité de conscience, l'égalité devant la loi et la neutralité du pouvoir politique), permettent d'affirmer que cette laïcité non seulement est loin de restreindre la liberté de religion, mais qu'elle est aussi une condition de possibilité de la liberté religieuse. Cette laïcité permettrait à chaque individu de décider lui-même du choix à faire quant à sa vie spirituelle et religieuse. L'égalité devant la loi proclamée par cette laïcité interdirait toute discrimination et l'État n'accorderait aucun privilège à aucune croyance spirituelle particulière (Cliteur, 2012, p. 130). Dans son article caractérisant la pratique des relations Église-État en France, qui s'appuie partiellement sur le rapport Stasi, Jean-Paul Willaime présente une vision différente de cette relation (Willaime, 2005).

31 Selon Timo Behr, «The rapport of the Stasi Commission and the law of 2004 seemingly brought to a conclusion any attempts to move towards a more multicultural model of society» (Behr, 2009, p. 174). 
What we have here is not a liberal-multiculturalist dilemma but a complete oxymoron: students who have chosen to be a part of the public education system are discouraged in the name of "laïcité" with the consequences of quitting or following curriculum from outside with the help of civil society organizations or turning to private schooling. The law is suspect of pushing students who have chosen to step out of their community, back to their community, back under the control of their brothers and fathers (Akan, 2009, p. 253).

Dans une perspective similaire, l'on trouve des études qui s'intéressent à l'utilisation, par les élites politiques, du concept de laïcité comme notion centrale de l'identité nationale, afin de répondre à la question de la diversité culturelle, notamment dans les débats entourant l'adoption de la loi française de 2004. L'analyse des arguments permettant de justifier cette loi, tant par le rapport Stasi que par les élites politiques, montrerait que la question du foulard islamique a été abordée à travers une symbolique influencée principalement par une version communautarienne du républicanisme. Qui plus est, la rhétorique de la commission Stasi révèlerait que, malgré le fait que la notion de communauté ait été utilisée péjorativement dans le rapport, la dimension communautarienne du républicanisme français y est dominante. Et si le rapport comporte des éléments libéraux (par exemple, l'exigence de la liberté de conscience, de l'égalité en droit des options religieuses et de la neutralité du pouvoir public), son argumentation visant l'interdiction des signes religieux à l'école contient une dimension «républicaine communautarienne», car la laïcité y est présentée comme une valeur culturelle, issue de l'histoire de la France et traduisant une conception du bien défendue par l'État. Dans le rapport, la fonction principale de la laïcité serait alors de réaffirmer l'unité de la nation et d'empêcher la désintégration sociale. Le communautarisme républicain, selon lequel la communauté politique repose sur l'identité collective nationale, relie la menace d'une dérive communautariste à la crainte d'un multiculturalisme différentialiste, où l'hétérogénéité culturelle de la société serait poussée à l'extrême :

La peur du «communautarisme» qu'expriment les partisans d'une loi sur la laïcité reflète donc en fait une conception de la société très marquée par un républicanisme «national-communautarien». Le Rapport Stasi fait en réalité, selon le vocabulaire utilisé ici, une critique «national-communautarienne» du multiculturalisme (Heine, 2009).

Cécile Laborde rejoint cette critique philosophique du rapport. Faisant la distinction entre le républicanisme du rapport Stasi et le républicanisme critique qu'elle défend, Laborde considère que les jugements de la commission sur le sens des signes religieux musulmans sont culturalistes et stéréotypés. Ils ne s'appuient ni sur la littérature sérieuse sur l'islam, ni sur l'avis des jeunes filles voilées. En effet, ces jugements n'ont comme fondement que le témoignage d'agents publics (chef d'établissements, enseignants, personnels de santé, etc.) 
se sentant menacés par des demandes d'accommodements. Or, employer ces témoignages pour justifier une loi coercitive soulève le spectre de la tyrannie de la majorité culturelle. Quant à la justification concernant l'incompatibilité intrinsèque existant entre l'expression religieuse et la neutralité de l'État, elle s'avère insuffisante pour interdire les signes religieux : d'un côté, les musulmans sont traités sévèrement (leurs demandes seraient qualifiées de préoccupantes, elles entraveraient le fonctionnement du service public) et, de l'autre, l'État français viole systématiquement le principe de neutralité lorsqu'il maintient, par exemple, le statut concordataire de l'Alsace-Moselle, cas dans lequel la laïcité est présentée comme un principe «appliqué avec empirisme». En outre, bien que le rapport Stasi souligne que l'État laïque a su faire des accommodements raisonnables favorisant les chrétiens et les juifs, il donne une interprétation inverse de cette notion lorsqu'il demande aux musulmans de mettre des limites à l'affirmation publique de leur identité. Or, en réalité, la charge des accommodements doit revenir aux institutions et non aux individus; elle implique non pas de mettre des bornes à l'identité, mais de l'affirmer dans la mesure du possible, à condition que cette demande n'entraîne pas une contrainte excessive. Au contraire, l'interprétation française considère comme légitimes, a priori, les lois et les règles existantes, sans examiner leur impact sur les minorités. Les musulmans sont ainsi assujettis à un devoir de réserve, «preuve de leur consentement "raisonnable" aux demandes du vivre-ensemble républicain» (Laborde, 2009, p. 27). C'est que le rapport Stasi souffre d'une tendance caractéristique du républicanisme français, qui consiste à juger la société française par des idéaux proclamés et les minorités par l'interprétation que l'on fait de leurs pratiques. En somme, le rapport Stasi «promeut un républicanisme conservateur, qui assimile les valeurs libérales, démocratiques et universelles, aux normes ethnoculturelles françaises, et juge les pratiques des minorités selon des critères qui ne font pas suffisamment la distinction entre les deux registres» (Laborde, 2009, p. 32).

Ce bref survol des analyses du rapport montre que la grande majorité des travaux examinés abordant la commission Stasi se sont concentrés notamment sur sa proposition d'interdire les signes religieux dans les écoles publiques, et sur la loi qui en a découlé. Parmi les aspects les plus fréquemment critiqués, on trouve la prépondérance de l'idéal d'assimilation dans le rapport, l'atteinte qu'il porte à la liberté religieuse, l'usage du principe de laïcité afin de justifier l'interdiction et le manque de preuves permettant de mesurer le danger auquel fait face la République. Certaines études présentent le rapport comme communautarien, incompatible avec le multiculturalisme, voire conservateur. Or, s'étant concentrée sur la recommandation de la commission Stasi concernant l'interdiction de porter des signes religieux, la littérature survolée a laissé inexplorés d'autres aspects du rapport. En prenant comme grille d'analyse les différentes positions républicaines examinées antérieurement, nous espérons montrer que la logique qui régit l'argumentation de cette proposition recoupe la position du républicanisme traditionnel, mais que le rapport s'en distingue par ailleurs, voire qu'il se rapproche du multiculturalisme. Qui plus est, au-delà 
de ces perspectives, un souci de dialogue interculturel est clairement repérable dans le rapport.

\subsection{Les trois républicanismes du rapport Stasi}

Le rapport Stasi formule une nette distinction entre les religions installées historiquement en France et les «nouvelles religions» qui s'y sont développées durant les dernières décennies. Les premières, richesses constitutives de la société française, ne représentent pas une menace pour la laïcité : elles ont su s'adapter à la laïcité, non sans combat, en particulier lorsqu'il s'agit de l'Église catholique. Quant aux «nouvelles religions», elles doivent trouver une place dans la société par le biais de l'intégration en évitant le repli communautaire; elles nécessitent «l'application du principe de laïcité renouvelée» (Stasi, 2003, p. 50). La question centrale du rapport est donc celle de savoir concilier l'unité de la société et le respect de la diversité devant cette nouvelle réalité dans laquelle l'islam occupe une place de toute première importance. C'est face à l'islam et, plus précisément, face aux dérives communautariennes de certains groupes islamistes, que la République doit agir de toute urgence. La notion de communauté en soi ne pose pas problème; le rapport distingue le fait communautaire du communautarisme (ibid., p. 54) et valorise largement la communauté nationale. C'est le «repli communautaire» qui sape les fondements du pacte social : aucun individu ne peut faire «primer l'allégeance à un groupe particulier sur l'appartenance à la République» (ibid., p. 45).

Le rapport partage donc avec le républicanisme traditionnel, ainsi qu'avec le républicanisme modernisé, ce grave souci du repli communautaire. Comme ces deux courants, il insiste sur le fait que la laïcité doit permettre le dépassement des «appartenances communautaires». Il craint que le «sentiment communautaire» puisse dériver vers un «communautarisme figé» menaçant la cohésion sociale, que les individus se juxtaposent «en une mosaïque de communautés fermées sur elles-mêmes» (ibid., p. 18). À l'instar des républicains traditionnels, le rapport identifie le multiculturalisme au communautarisme. Il constate que les Pays-Bas, ayant mis en place des politiques multiculturelles, ont regretté la «logique communautaire» adoptée, car elle était source de problèmes tels que la tribalisation ou le regroupement dans des «quartiers communautaires», favorisant l'endogamie.

Le rapport partage également avec la position des républicains traditionnels l'idée selon laquelle certaines revendications religieuses menacent la stabilité de la République. La laïcité y apparaît comme affaiblie, menacée par des revendications tendant à faire prévaloir des «convictions communautaires», ainsi que par des «groupes communautaristes» qui, afin de mobiliser des militants, exploitent le malaise social dans des quartiers favorables au développement de «logiques communautaristes» (ibid., p. 45). La commission est consciente que les difficultés rencontrées étaient «encore minoritaires»; néanmoins, elle souligne qu' «elles sont réelles, fortes et annonciatrices de dysfonctionnements, d'autant plus que la diffusion récente et rapide de ces phénomènes est préoccupante» (ibid., p. 40). 
À l'école, où les élèves doivent faire face aux «pressions et aux instrumentalisations des activistes politico-religieux», trouver un remède «est une urgence sociale» (Stasi, 2003, p. 15). L'ordre public est troublé justement dans cet espace où les élèves doivent être protégés de la «fureur du monde» (ibid., p. 56). L'État doit agir pour empêcher «que leur esprit soit harcelé par la violence et les fureurs de la société» et par les «passions du monde» (ibid., p. 14). En effet, à l'école, «le port d'un signe religieux ostensible - grande croix, kippa ou voile — suffit déjà à troubler la quiétude de la vie scolaire» (ibid., p. 41). Pourtant, les difficultés ne se limitent pas au seul port du voile : les demandes d'absence, les interruptions de cours pour des motifs religieux, le refus des filles de se soumettre aux contrôles d'identité par un examinateur masculin troublent la quiétude scolaire. Même s'il s'agit d'une «minorité activiste», ces attitudes portent gravement atteinte aux principes régissant le service public. Qui plus est, les professeurs protestent lorsqu'ils voient des mères d'élèves porter le foulard dans le cadre d'une sortie scolaire. Les personnels se sentent désemparés, en situation de désarroi; ne pouvant plus accomplir leur mission, ils sont affectés moralement, font état de mal-être, de malaise, de souffrance. Ils ont le «sentiment» que les règles ne sont pas claires, que le soutien que leur apporte la hiérarchie est faible. Ils se sentent victimes d'une guérilla «permanente contre la laïcité» (ibid., p. 44). Seuls devant ces situations, «ils contestent les chiffres officiels qui minimisent les difficultés rencontrées sur le terrain» (ibid., p. 57); ils constatent les tensions que suscitent les revendications identitaires et religieuses, la formation de clans, les «regroupements communautaristes dans les cours de récréation» (ibid., p. 58). Dans le même sens, ils demandent l'interdiction des signes religieux pour «que le chef d'établissement ne soit confronté seul à la question de déterminer s'il se trouve face à un signe ostentatoire» (ibid., p. 58).

Après avoir entendu, d'une part, des représentants de grandes religions et des dirigeants d'associations des droits de l'homme s'opposant à l'interdiction des signes religieux et, d'autre part, «la quasi totalité des chefs d'établissements et de très nombreux professeurs» demandant l'interdiction, la commission a estimé que la question ne relevait plus de «la liberté de conscience, mais [de] l'ordre public»: d'un côté, le déroulement normal des enseignements ne pouvait plus être assuré; de l'autre, «des pressions» s'exerçaient sur des filles mineures pour les obliger à porter un signe religieux. Dans ces circonstances, la République ne pouvait donc rester indifférente au «cri de détresse» de ces filles. «L'espace scolaire doit rester un lieu de liberté et d'émancipation» (Stasi, 2003, p. 58).

Voici, résumés brièvement, les arguments justifiant l'interdiction des signes religieux dans les écoles publiques. Cette argumentation partage avec celle des républicains traditionnels les idées suivantes :

a) la société est un espace d'affrontement des convictions religieuses et l'école est le lieu où doivent cesser ces affrontements; 
b) le seul port du foulard suffit pour troubler l'ordre public;

c) la laïcité est affaiblie et menacée par des revendications religieuses;

d) même si les difficultés rencontrées son minoritaires, elles constituent une grave menace pour l'avenir;

e) il existe donc une urgence sociale qui appelle à des mesures urgentes;

f) l'une de ces mesures consiste à interdire les signes religieux; et

g) cette interdiction protège les jeunes filles des pressions communautaristes.

Ils ont également en commun la particularité de ne pas donner de chiffres permettant de mesurer le danger réel auquel se trouve exposée la République, leur argumentation reposant sur des généralisations.

Ceci dit, le rapport se distingue du républicanisme traditionnel sous certains aspects. Tout d'abord, même si l'interdiction des signes religieux semble être le corollaire d'une laïcité de combat, la commission prône une laïcité ouverte et dynamique. Elle estime que «le temps de la laïcité de combat est dépassé, laissant la place à une laïcité apaisée» (Stasi, 2003, p. 36). Pour répondre aux nouveaux défis posés par la diversité culturelle et religieuse, «la laïcité ne doit pas être sur la défensive; elle ne peut se décliner sur le mode de la forteresse assiégée» (ibid., p. 36). Ensuite, tout en partageant avec les républicains traditionnels la crainte du repli communautariste, le rapport dénonce l'illusion d'un «pacte républicain désincarné» (ibid., p. 18) et accepte le défi de forger l'unité dans le respect de la diversité. Dans une recherche d'équilibre, le rapport évite ainsi la polarisation. Enfin, à la différence du républicanisme traditionnel, qui contestait la légitimé des arguments fondés sur les droits de l'homme pour défendre le droit de porter le foulard, la commission se préoccupe de justifier l'interdiction du voile en vertu des conditions fixées par la Convention européenne des droits de l'homme et des libertés fondamentales (ibid., p. 59).

D'autres éléments, qui permettent de constater un éloignement de la commission par rapport au républicanisme traditionnel, semblent la rapprocher de certains aspects du républicanisme modernisé, voire du républicanisme multiculturel, dans ce que ces deux courants ont de commun. Avant d'examiner ce rapprochement, rappelons que le républicanisme modernisé représente une sorte de posture intermédiaire entre les deux autres positions. Ses frontières étant floues, le républicanisme modernisé reste attaché au républicanisme traditionnel par certains aspects, tandis que par d'autres, il partage des points de vue propres au républicanisme multiculturel. Le rapport se montre ainsi proche des républicanismes traditionnel et modernisé dans leur vision forte de la citoyenneté, en ce qu'il appelle au dépassement des appartenances et insiste sur les obligations des citoyens (Stasi, 2003, p. 15). Il considère que, dans une société laïque, chacun doit pouvoir prendre des distances par rapport à sa propre tradition (ibid., p. 17). Il affirme que la force de l' «identité culturelle française peut favoriser le creuset de l'intégration» (ibid., p. 35), que la laïcité touche l'identité nationale (ibid., p. 36) et qu'elle peut être le levain de l'intégration de tous dans la société (ibid., p. 18). Dans le même sens, il conteste tout ce 
qui sape non seulement la confiance dans la République, mais également «l'identification à la nation» (ibid., p. 46).

Toutefois, le rapport tend vers ce que partagent les républicanismes modernisé et multiculturel. Il refuse, par exemple, que les choix religieux doivent être privatisés «et que leur soient déniées toute dimension sociale ou capacité d'expression publique» (ibid., p. 13). La libre expression spirituelle ou religieuse dans l'espace public y est présentée comme légitime, voire comme essentielle au débat démocratique : «les représentants des différentes options spirituelles sont fondés à intervenir à ce titre dans le débat public, comme toute composante de la société» (ibid., p. 13).

À l'instar des républicanismes modernisé et multiculturel, le rapport considère comme un «progrès» la tendance du gouvernement français à ne pas rester dans l'égalité formelle et à favoriser l'égalité réelle, adoptant, dans la pratique, des accommodements raisonnables. Parmi les mesures saluées par la commission figurent le fait que les pouvoirs publics prennent en compte les exigences liées à l'organisation des fêtes religieuses, telles que Aïd-el-Kebir et Kippour; que des locaux communaux soient mis à la disposition d'organisations communautaires; que le calendrier des fêtes religieuses soit diffusé à l'ensemble des administrations chaque année, et que celles-ci accordent l'autorisation d'absences. La commission approuve également que les interdits alimentaires liés aux convictions religieuses soient pris en compte par les administrations : davantage que par le passé, les cantines des écoles, des hôpitaux et des prisons offrent des menus diversifiés. Enfin, le rapport salue le fait que les municipalités mettent moins d'obstacles à l'édification des lieux de cultes et que l'abattage rituel commence à être mieux assuré (Stasi, 2003, p. 38-39).

De surcroît, la commission ne se contente pas d'énumérer ces constats. Elle encourage le gouvernement français à «poursuivre les améliorations» (ibid., p. 39). Elle dénonce les difficultés existant encore lorsqu'il s'agit de prendre des jours de congé lors des grandes fêtes musulmane et juive, et conteste le fait que des contrôles soient organisés dans les écoles en ces jours de fêtes, «privant ceux qui ont été autorisés à s'absenter de la possibilité d'y participer» (Stasi, 2003, p. 39). En conséquence, elle estime que, sans remettre en cause le calendrier catholique, la République s'honorerait

en reconnaissant les jours les plus sacrés des deux autres grandes religions monothéistes présentes en France, les bouddhistes organisant leur fête annuelle principale un dimanche de mai. Ainsi à l'école, l'ensemble des élèves ne travailleraient pas les jours de Kippour et de l'Aïd-el-Kébir. Ces deux jours fériés supplémentaires devraient être compensés (ibid., p. 65).

Notons au passage qu'il ne s'agit pourtant pas «de remettre en cause la place historique que tiennent la culture et les confessions chrétiennes dans la société» (ibid., p. 62); il s'agit plutôt de garantir la pleine liberté de culte de toutes les options spirituelles, dans le cadre de la laïcité française. 
Le rapport désapprouve également le fait qu'il n'y ait pas suffisamment d'aumôniers musulmans dans les hôpitaux ou dans les prisons, et qu'il n'y en ait ni dans les établissements scolaires, ni dans l'armée. Constatant que «certaines mesures favorisent des religions spécifiques qui ne disposent pas des mêmes moyens que les autres», le rapport propose qu'on nomme un aumônier général musulman «dans les mêmes conditions que les aumôniers généraux des autres religions» (Stasi, 2003, p. 64), et que l'on recrute des aumôniers dans les prisons et dans l'armée (ibid., p. 67). Il regrette que, notamment dans les hôpitaux, la toilette funéraire des morts ne soit pas toujours assurée «dans le respect des règles religieuses, même lorsque celles-ci sont compatibles avec les nécessités de l'ordre public et les contraintes de service», et qu'il soit parfois impossible d'enterrer des morts «conformément aux traditions religieuses et dans le respect des lois de la République» (ibid., p. 40). Ainsi, s'attaquant à l'usage que font de la laïcité les autorités publiques lorsqu'elles refusent l'orientation des tombes dans les cimetières, la commission propose «que le ministère de l'intérieur invite au respect des convictions religieuses, notamment à l'occasion de l'expiration des concessions funéraires. En liaison avec les responsables religieux, la récupération des concessions doit se faire dans des conditions respectueuses des exigences confessionnelles, avec un aménagement des ossuaires adapté» (ibid., p. 65). Les convictions religieuses doivent également être respectées en matière alimentaire, «des substituts au porc et le poisson le vendredi doivent être proposés dans le cadre de la restauration collective (établissements scolaires, pénitentiaires, hospitaliers, d'entreprise)», à condition que la prise en compte de ces exigences religieuses soit compatible avec le bon fonctionnement du service, «selon le principe que les Québécois appellent "accommodement raisonnable"» (ibid., p. 64).

Le rapport se prononce également en faveur du financement étatique de structures communautaires et religieuses. Il va ainsi plus loin que le républicanisme modernisé, pour qui le rôle de l'État n'est pas de subventionner les communautés culturelles ou religieuses, et qui préfère laisser aux communautés le poids de leur propre subsistance. Cependant, la condition que la commission établit pour un tel financement s'accorde parfaitement avec les aspirations des républicanismes modernisé et multiculturel. En effet, pour le premier, l'organisation sociale doit soutenir les échanges, les institutions communes devant encourager l'ouverture des groupes (Schnapper, 2004, p. 181). Pour le second, le multiculturalisme tempéré à appliquer en France implique justement d'organiser la confrontation entre groupes pour éviter le repli sur soi des différences (Roman, 1996, p. 20). Cette dimension interculturelle non seulement se trouve dans le rapport Stasi, mais elle est la condition même de l'attribution d'aides financières aux communautés culturelles : «oui au financement de celles qui favorisent les échanges, les rencontres, l'ouverture sur la cité; non à l'aide aux associations qui refusent le dialogue avec le reste de la société» (Stasi, 2003, p. 54). Constatant que «le brassage social, l'apprentissage du vivre ensemble, le respect des différences culturelles et spirituelles dans 
un cadre laïque» ne peut pas être assuré par l'école à elle seule, la commission recommande d'instaurer un service civil (ibid., p. 52) et d'accorder la priorité aux équipements sportifs communs favorisant le brassage social (ibid., p. 67).

Certains aspects de la dimension interculturelle du rapport Stasi recouperont, ne serait-ce que partiellement, des recommandations de deux autres commissions proposant l'interculturalité comme modèle de société en Belgique. En effet, tant la Commission du dialogue interculturel (2005) que les Assises de l'interculturalité (2010) défendent l'engagement dans une dynamique sociale qui facilite l'interaction, la rencontre et le dialogue entre cultures. Leur conception interculturelle implique que la mixité culturelle soit favorisée et que les croyances les plus différentes puissent être accueillies sans pour autant renoncer aux valeurs démocratiques rendant le dialogue possible. Les deux commissions formulent d'ailleurs des recommandations similaires à celles de la commission Stasi, comme la prise en compte des fêtes religieuses (Delruelle et Torfs, 2005, p. 77; Foblets et Kulakowski, 2010, p. 69), l'enseignement de certaines langues d'origine dans les écoles (Stasi, 2003, p. 67; Delruelle et Torfs, 2005, p. 90; Foblets et Kulakowski, 2010, p. 44), l'intégration de l'histoire des peuples, des migrations et des cultures dans les programmes scolaires (Stasi, 2003, p. 55; Delruelle et Torfs, 2005, p. 89; Foblets et Kulakowski, 2010, p. 39), la création d'une Charte («de la Laïcité» en France, «de la citoyenneté» en Belgique) définissant les droits et les obligations de chacun, mais dépourvue de valeur juridique dans le deux cas. Finalement, les trois commissions se montrent favorables à l'enseignement du fait religieux dans les écoles publiques (Stasi, 2003, p. 63; Delruelle et Torfs, 2005, p. 92; Foblets et Kulakowski, 2010, p. 40), considérant qu'il favorise la compréhension des différentes cultures et traditions religieuses.

\section{Conclusion}

Nous avons analysé le rapport Stasi à la lumière de trois positions républicaines sur la diversité développées en France dans les années 90. Une première position, attachée au modèle d'assimilation et à la laïcité de combat, se prononce contre les politiques de reconnaissance publique de la diversité, contre les droits culturels et contre le multiculturalisme en tant que politique gouvernementale, sous prétexte que ces politiques conduisent à la fragmentation sociale, au repli identitaire et à l'égalité juridique. Cette position se prononce également en faveur de l'interdiction des signes religieux dans les écoles, estimant que le foulard est un signe de l'oppression communautarienne. Les filles portant le foulard se trouveraient manipulées et empêchées d'accéder à l'autonomie, cette dernière étant censée être garantie par l'école. La deuxième position partage avec la première l'idée selon laquelle l'intégration sociale implique l'identification à la nation en tant que principe universel, permettant le dépassement des particularités et le distancement critique vis-à-vis de la tradition particulière. Estimant que le rôle premier de l'État est de garantir 
l'égalité formelle, cette position accepte pourtant que certains droits culturels soient accordés afin de favoriser l'égalité réelle, à condition que l'ordre public ne soit pas affecté et que les droits de l'homme soient respectés. Elle s'oppose au financement public des organisations communautaires. Enfin, la troisième position prône un multiculturalisme tempéré comme modèle d'intégration pour la France. Elle défend les droits culturels et la reconnaissance publique de la diversité. Considérant légitimes les revendications culturelles et religieuses, cette perspective soutient que les accommodements raisonnables et les mesures de discrimination positive sont nécessaires afin de garantir l'accès de tous les citoyens à l'égalité réelle, l'égalité formelle étant insuffisante. Mettant de l'avant le besoin des individus de se référer à leur culture, le multiculturalisme tempéré s'oppose à l'interdiction des signes religieux dans les écoles publiques.

Notre analyse du rapport Stasi montre que la plupart des études qui le qualifient d'assimilationniste et d'anti-multiculturaliste, ignorent certains aspects importants du rapport, peut-être en raison de leur concentration sur l'une des 26 recommandations qu'il a formulées : celle concernant l'interdiction des signes religieux dans les écoles. Cependant, si le rapport, notamment dans l'argumentation justifiant cette interdiction, reste très proche du républicanisme traditionnel, il a également certains points communs avec les deux autres républicanismes examinés. En effet, il est difficile de lui adresser la critique, formulée par Khosrokhavar (1997) au sujet de l'«universalisme abstrait», selon laquelle un espace public homogène serait désirable, les particularismes religieux et culturels devant s'exprimer dans la sphère privée. De plus, loin de refuser la possibilité de recourir à des mécanismes particularistes et communautaires, le rapport propose l'égalisation des conditions en ce qui concerne le financement public des structures communautaires, encourage l'égalité réelle suivant la voie des accommodements raisonnables, et formule certaines recommandations visant des modifications institutionnelles. Parmi ces dernières, rappelons celles visant à adopter des menus dans les écoles en fonction des particularismes religieux, à faire des fêtes Kippour et Aïd-el-Kebir des jours fériés «dans toutes les écoles de la République» et à inclure certaines langues non étatiques, y compris l'arabe, dans l'éducation nationale. Ces mesures non seulement recoupent celles qui seront proposées par des commissions ouvertement interculturelles, mais elles prennent aussi en compte le besoin de l'individu de se référer à une culture l'instituant dans sa différence, conformément aux exigences des républicains multiculturalistes (Roman, 1995). À l'instar du républicanisme modernisé, les critères conditionnant ces mesures sont le respect de l'ordre public et celui des droits fondamentaux. Néanmoins, lorsqu'il a fallu se prononcer sur la question du foulard, la commission a estimé que la question ne relevait plus de la liberté de conscience, mais de l'ordre public. Et comme les républicains traditionnels, elle a tranché en faveur de l'ordre public, au détriment du droit à la liberté de conscience. 


\section{Références bibliographiques}

Adelman, Howard

2011 «Contrasting Commissions on Interculturalism: The Hijab and the Workings of Interculturalism in Quebec and France», Journal of Intercultural Studies, vol. 32, no 3, p. 245-259.

Adrian, Melanie

2006 «Laïcité Unveiled: A Case Study in Human Rights, Religion, and Culture in France», Human Rights Review, vol. 8, nº 1, p. 102-114.

Agier-Cabanes, Isabelle

2007 «La laïcité, exception libérale dans le modèle français», Cosmopolitiques, vol. 16, p. 133-144.

Akan, Murat

2009 «Laïcité and Multiculturalism: the Stasi Report in Context», The British Journal of Sociology, vol. 60, n 2, p. 237-254.

Annales du Sénat.

1883 Débats parlementaires. Section ordinaire de 1883. Tome II. Du 19 Avril au 2 Aout 1883. Paris, Imprimerie du journal officiel, quai Voltaire.

Badinter, Elisabeth, Régis Debray, et al.

1989 «Profs, ne capitulons pas!», Le Nouvel Observateur, 2-8 novembre.

Baubérot, Jean

2004 «La Commission Stasi vue par l'un de ses membres», French Politics, Culture et Society, vol. 22, no 23, p. 135-141.

Baubérot, Jean

2008 «La Commission Stasi : entre laïcité républicaine et multiculturelle», Historical Reflections, vol. 34, no 3, p. 8-20.

Baubérot, Jean

2009 «L'évolution de la laïcité en France : entre deux religions civiles», Diversité urbaine, vol. 9, n 1, p. 9-25.

Baubérot, Jean

2012 «Le dernier Curiace. Un sociologue dans la commission Stasi», dans Pauline Côté et Jeremy Gunn, dir., La nouvelle question religieuse. Régulation ou ingérence de l'État? Bruxelles, P.I.E-Peter Lang, p. 247-272.

Baudouin, Jean et Philippe Portier

2001 «La laïcité française. Approche d'une métamorphose», dans Jean Baudoin et Philippe Portier, dir., La laïcité, une valeur d'aujourd'hui. Contestations et renégociations du modèle, Rennes, Presses universitaires de Rennes, p. 15-34.

Behr, Timo

2009 France, Germany and Europe's Middle East Dilemma: The Impact of National Foreign Policy Traditions on Europe's Middle East Policy, Thèse de doctorat, Baltimore, The Johns Hopkins University. 
Belbah, Mustaph et Claire de Galembert

2008 «Dialogue avec l'abstentionniste de la commission Stasi. Entretien avec Jean Baubérot», Droit et société, vol. 1, nº 68, p. 237-249.

Bouchard, Gérard

2012 L'interculturalisme. Un point de vue québécois, Montréal, Boréal.

Bouchard, Gérard et Charles Taylor

2008 Fonder l'avenir : le temps de la conciliation. Rapport de la Commission de consultation sur les pratiques d'accommodement reliées aux différences culturelles, Québec, Gouvernement du Québec.

Bourdeau, Vincent

2007 «Un républicanisme du gaz et de l'eau courante», dans Vincent Bourdeau et Roberto Merrill, dir., La République et ses démons. Essais de républicanisme appliqué, Paris, Ère, p. 13-41.

Buisson, Ferdinand

1887 Dictionnaire de pédagogie et d'instruction primaire, Première partie, Tome second, Paris, Librairie Hachette.

Chaudhary, Ajay S.

2005 «"The Simulacra of Morality": Islamic Veiling, Religious Politics and the Limits of Liberalism», Dialectical Anthropology, vol. 29, nos 3/4, p. 349-372.

Chevènement, Jean-Pierre

1989 «La politique, les principes et la volonté», Le Monde, 9 novembre, p. $1-2$.

Choudhury, Nusrat

2007 «From the Stasi Commission to the European Court of Human Rights: L'Affaire du Foulard and the Challenge of Protecting the Rights of Muslim Girls», Columbia Journal of Gender and Law, vol. 16, $\mathrm{n}^{\circ} 1$, p. 199-296.

Cliteur, Paul

2012 «State and Religion against the backdrop of religious Radicalism», $I \bullet C O N$, vol. $10, \mathrm{n}^{\mathrm{0}} 1$, p. $127-152$.

Coq, Guy

1989 «Espace laïque», Le Monde, 24 octobre, p. 2.

Coq, Guy

1995 Laïcité et République. Le lien nécessaire, Paris, Éditions du Félin.

Coq, Guy

2005 «Un principe universel», Hommes et Migrations, novembre-décembre, $\mathrm{n}^{\mathrm{o}} 1258$, p. 6-11.

Coq, Guy

2012 «La laïcité et l'école de la République», Tréma, vol. 37, p. 2-16.

Crépon, Sylvain

2008 «La lutte pour la reconnaissance des signes religieux à l'école. Une étude comparative France-Belgique», Politique européenne, vol. 1, $\mathrm{n}^{\mathrm{o}} 24$, p. 83-101. 
Debray, Régis

1989a Que vive la République, Paris, Odile Jacob.

Debray, Régis

1989b «Êtes-vous démocrate ou républicain?», Le Nouvel observateur, 30 novembre.

Debray, Régis, Max Gallo, Jacques Juillard, et al.

1998 «Républicains, n’ayons plus peur!» Le Monde, 4 septembre, p. 13.

Delruelle, Edouard et Rik Torfs

2005 Rapport de la Commission du dialogue interculturel. Rapport final et livre des auditions, Bruxelles, Ministère de l'Égalité des Chances, de l'Intégration sociale et de l'Interculturalité.

Doyle, Natalie J.

2011 «Lessons from France: Popularist Anxiety and Veiled Fears of Islam», Islam and Christian-Muslim Relations, vol. 22, $\mathrm{n}^{\circ}$ 4, p. 475-489.

Finkielkraut, Alain

1989a «La France disparaît au profit des tribus. Entretien avec Thomas Ferenczi», Le Monde, 13 juillet, p. 13.

Finkielkraut, Alain

1989b «La sainte alliance des clergés», Le Monde, 25 octobre, p. 2.

Foblets, Marie-Claire et Christine Kulakowski

2010 Les Assises de l'Interculturalité, Bruxelles, Ministère de l'Emploi et de l'Égalité des Chances.

Fraser, Nancy

2000 «Rethinking recognition», The New Left Review, vol. 3, May-June, p. $107-120$.

Fraser, Nancy

2005 Qu'est-ce que la justice sociale? Reconnaissance et redistribution, Paris, La Découverte/Poche.

Freedman, Jane

2004 «Secularism as a Barrier to Integration? The French Dilemma», International Migration, vol. $13, \mathrm{n}^{\circ}$ 42(3), p. 5-27.

Galeotti, Anna E.

2002 Toleration as Recognition, Cambridge, Cambridge University Press.

Gaspard, Françoise et Farhad Khosrokhavar

1995 Le foulard et la République, Paris, La Découverte.

Gedicks, Frederick Mark

2006 «Religious Exemptions, Formal Neutrality, and Laïcité», Indiana Journal of Global Legal Studies, vol. 13, nº 42, p. 473-492.

Gemie, Sharif

2004 «Stasi's Republic: The School and the 'Veil': December 2003-March 2004», Modern and Contemporary France, vol. 12, n 3, p. 387-397.

Guérard de Latour, Sophie

2009 Vers la république des différences, Toulouse, Presses universitaires du Mirail. 
Gutmann, Amy

1994 Multiculturalism and the Politics of Recognition, Princenton, Princenton University Press.

Habermas, Jürgen

1998 L'intégration républicaine, Paris, Fayard.

Hayat, Pierre

2013 «La laïcité républicaine. Déterminations, implications et enjeux», Le Philosophoire, vol. 1, n 39, p. 31-44.

Heine, Sophie

2009 «The Hijab Controversy and French Republicanism: Critical Analysis and Normative Propositions», French Politics, vol. 7, n 2, p. 167-193.

Honneth, Axel

2013 La lutte pour la reconnaissance, Paris, Folio.

Honohan, Iseult

2007 «Civic republicanism and the multicultural city», dans William Neill et Hanns-Uve Schwedler, dir., Migration and Cultural Inclusion in the European City, Basingstoke, Palgrave Macmillan, p. 63-73.

Hunter-Henin, Myriam,

2012 «Why the French don't Like the Burqa: Laïcité, National Identity and Religious Freedom», International and Comparative Law Quarterly, vol. $61, n^{\circ} 3$, p. 613-639.

Jacquemain, Marc

2014 «La laïcité contre elle-même», dans Collectif Tayush, Les défis du pluriel. Égalité, diversité, lä̈cité, Bruxelles, Couleur Livres, p. 115-124.

Jelen, Christian

1997 «La régression multiculturaliste», Le Débat, vol. 5, n 97, p. 137-143. Jennings, Jeremy

2000 «Citizenship, Republicanism and Multiculturalism in Contemporary France», British Journal of Political Science, vol. 30, nº 4, p. 575-597.

Jennings, Jeremy

2011 Revolution and the Republic. A History of Political Thought in France since the Eighteenth Century, Oxford, Oxford University Press.

Khosrokhavar, Farhad

1997 «L'universel abstrait, le politique et la construction de l'islamisme comme forme d'altérité», dans Michel Wieviorka, dir., Une société fragmentée? Paris, La Découverte, p. 113-151.

Laborde, Cécile

2001 «The Culture(s) of the Republic: Nationalism and Multiculturalism in French Republican Thought», Political Theory, vol. 29, $\mathrm{n}^{\mathrm{0}} 5$, p. 716-735.

Laborde, Cécile

2009 «Républicanisme critique vs républicanisme conservateur : repenser les "accommodements raisonnables"», Critique internationale, vol. 3, no 44 , p. 19-33. 
Laborde, Cécile

2010 Français, encore un effort pour être républicains, Paris, Seuil.

Lacroix, Justine

2003 Communautarisme versus libéralisme. Quel modèle d'intégration politique? Bruxelles, Éditions de l'Université de Bruxelles.

Landfried, Julien

2007 Contre le communautarisme, Paris, Armand Colin.

Leane, Geoffrey W.G.

2011 «Rights of Ethnic Minorities in Liberal Democracies: Has France Gone Too Far in Banning Muslim Women from Wearing the Burka?» Human Rights Quarterly, vol. 33, no 4, p. 1032-1061.

Liogier, Raphaël

2009 «Laïcité on the Edge in France: Between the Theory of Church-State Separation and the Praxis of State-Church Confusion», Macquarie Law Journal, vol. 9, n 25-45.

Maclure, Jocelyn et Charles Taylor

2010 Laïcité et liberté de conscience, Montréal, Boréal.

Maynor, John

2003 Republicanism in the Modern World, Cambridge, Polity Press.

Milot, Micheline

2013 «Dualisme des conceptions de la laïcité au Québec et en France», The Tocqueville Review/La revue Tocqueville, vol. 3, n 1, p. 17-42.

Morag, Patrick

2000 «Liberalism, rights and recognition», Philosophy \& Social Criticism, vol. $26, n^{\circ} 5$, p. $28-46$.

Pelletier, Denis

2005 «L'École, l'Europe, les corps : la laïcité et le voile», Vingtième Siècle. Revue d'histoire, vol. 87, p. 159-176.

Portier, Philippe

2002 «De la séparation à la reconnaissance. L'évolution du régime français de laïcité», dans Jean-Robert Armogathe et Jean-Paul Willaime, dir., Les mutations contemporaines du religieux, Turnhout, Brepols, p. $1-24$.

Ricœur, Paul

2004 Parcours de la reconnaissance, Paris, Folio/Gallimard.

Roman, Joël

1990 «La fin du modèle républicain», Esprit, vol. 164, p. 67-79.

Roman, Joël

1995 «Un multiculturalisme à la française», Esprit, vol. 212, p. 145-160.

Roman, Joël

1996 «Pour un multiculturalisme tempéré», Hommes et Migrations, vol. 1197, p. 18-22.

Roman, Joël

1998 La démocratie des individus, Paris, Calmann-Lévy. 
Roman, Joël

2006 Eux et nous, Paris, Hachette.

Schnapper, Dominique

1994 La communauté des citoyens. Sur l'idée moderne de nation, Paris, Gallimard.

Schnapper, Dominique

1998 La relation à l'autre, Paris, Gallimard.

Schnapper, Dominique

2004 «La République face aux communautarismes», Études, vol. 400, n 2 , p. $177-188$.

Schnapper, Dominique

2007 Qu'est-ce que l'intégration? Paris, Gallimard.

Stasi, Bernard

2003 Rapport de la Commission de réflexion sur l'application du principe de laïcité dans la République, Paris, La documentation française.

Taguieff, Pierre-André

2003 «Multiculturalisme et communautarisme devant les principes républicains», Le Figaro, 17 juillet.

Taylor, Charles

1994 «The Politics of Recognition», dans Amy Gutmann, dir., Multiculturalism, Princeton, Princeton University Press.

Terray, Emmanuel

2004 «La question du voile : une hystérie politique», Mouvements, vol. 2, n 32 , p. 96-104.

Tévanian, Pierre

1999 «Quelques remarques sur l’idéologie "national-républicaine"», Lignes, vol. $2, n^{\circ} 37$, p. 102-116.

Thomas, Carole

2008 «Interdiction du port du voile à l'école : pratiques journalistiques et légitimation d'une solution législative à la française», Politique et Sociétés, vol. 27, no 2, p. 41-71.

Thomas, Elaine R.

2006 «Keeping Identity at a Distance: Explaining France's New Legal Restrictions on the Islamic Headscarf», Ethnic and Racial Studies, vol. $29, n^{\circ} 2$, p. 237-259.

Todd, Emmanuel

1994 Le destin des immigrés. Assimilation et ségrégation dans les démocraties occidentales, Paris, Seuil.

Triki-Yamani, Amina et Marie Mc Andrew

2009 «Reconnaissance de la diversité religieuse : débats actuels dans différentes sociétés», Diversité urbaine, vol. 9, n 1, p. 73-94.

Tully, James

2001 «La conception républicaine de la citoyenneté dans les sociétés multiculturelles et multinationales», Politique et Sociétés, vol. 20, nº 1, p. 123-146. 


\section{Dialogue}

Tully, James

2004 «Recognition and Dialogue: the Emergence of a New Field», Critical Review of International Social and Political Philosophy, vol. 7, $\mathrm{n}^{\circ} 3$, p. 84-106.

Vichniac, Judith E.

2008 «Jewish Identity Politics and the Scarf Affairs in France», French Politics, Culture \& Society, vol. 26, n 1, p. 111-128.

Weil, Patrick

2005 «Lever le voile», Esprit, janvier, p. 45-53.

Wieviorka, Michel

2011 «Quand la gauche va-t-elle défendre le multiculturalisme?» Blog Rue89, Chez Michel Wieviorka, en ligne, <http://blogs.rue89.nouvelobs.com/ wieviorka/2011/02/12/quand-la-gauche-va-t-elle-defendre-lemulticulturalisme-190273>.

Wieviorka, Michel

2013 «Le mythe français», La Presse, 14 septembre 2013.

Willaime, Jean-Paul

2005 «1905 et la pratique d'une laïcité de reconnaissance sociale des religions», Archives de sciences sociales des religions, vol. 129, p. 67-82. 